AperTO - Archivio Istituzionale Open Access dell'Università di Torino

Magnetic fabric in carbonatic rocks from thrust shear zones: A study from the Northern Apennines (Italy)

This is a pre print version of the following article:

Original Citation:

Availability:

This version is available http://hdl.handle.net/2318/1766134

since 2021-01-08T16:57:12Z

Published version:

DOI:10.1016/j.tecto.2020.228573

Terms of use:

Open Access

Anyone can freely access the full text of works made available as "Open Access". Works made available under a Creative Commons license can be used according to the terms and conditions of said license. Use of all other works requires consent of the right holder (author or publisher) if not exempted from copyright protection by the applicable law. 


\section{Magnetic Fabric in Thrust Shear Zones: A Study from the Northern Apennines (Italy)}

Sara Satolli ${ }^{\mathrm{a}, \mathrm{b},{ }^{*}, \text { Claudio Robustelli Test }}{ }^{\mathrm{b}, \mathrm{c}}$, Dorota Staneczek ${ }^{\mathrm{d}}$, Elena Zanella ${ }^{\mathrm{b}, \mathrm{c}}$, Fernando Calamita $^{a}$, Evdokia Tema ${ }^{\text {b,c }}$

a Dipartimento di Ingegneria e Geologia, Università degli Studi “G. d’Annunzio" di Chieti-Pescara, via dei Vestini 31, 66100 Chieti, Italy

b CIMaN-ALP, Centro Interuniversitario di Magnetismo Naturale - Alpine Laboratory of Paleomagnetism, via Luigi Massa 4, 12016 Peveragno, Italy

c Dipartimento di Scienze della Terra, Università degli Studi di Torino, via Valperga Caluso 35, 10125 Torino, Italy

d Institute of Geophysics, Polish Academy of Sciences, Księcia Janusza 64, 01-452, Warszawa, Poland

Corresponding author at: Dipartimento di Ingegneria e Geologia, Università degli Studi "G. d'Annunzio" di Chieti-Pescara, via dei Vestini 31, 66100 Chieti, Italy, Tel.: 003908713556427 , email address: sara.satolli@unich.it 


\section{ABSTRACT}

We present the results of an integrated structural and anisotropy of magnetic susceptibility (AMS) investigation in thrust shear zones. A total of 17 sites from six localities along the frontal and oblique ramp of the Olevano-Antrodoco-Sibillini thrust and back thrust (Northern Apennines, Italy) were studied to investigate both magnetic fabric and structural characteristics of Cretaceous to Neogene calcareous and marly rocks. In most of the sites AMS is controlled by the paramagnetic minerals (prevailingly phyllosilicates). Structural analysis shows the presence of SC- and Stectonites associated to predominant simple and pure shear, respectively. The combination of density diagrams and cluster analysis allowed discriminating different sedimentary/tectonic overprints on a blended magnetic fabric. Six different subfabrics were distinguished, related to the structural data and associated to deformation stages and regimes. The magnetic foliation has a double tendency to parallelize to pressure solution cleavage (S) and shear planes (C). The magnetic lineation tends to progressively align with the slip vector, save for pure-shear-dominated sites at less than $15-20 \mathrm{~cm}$ from the thrust, where it aligns with the transport direction. The magnetic fabric is dominated by simple shear deformation. The protocol applied for AMS analysis shows a great potential to unravel blended sedimentary and/or tectonic features in magnetic fabrics. AMS can be considered as a useful tool in unravelling the variation of simple-pure shear deformation regime in shear zones.

Keywords: Magnetic fabric; Structural geology; Pure shear; Simple shear; Tectonites 


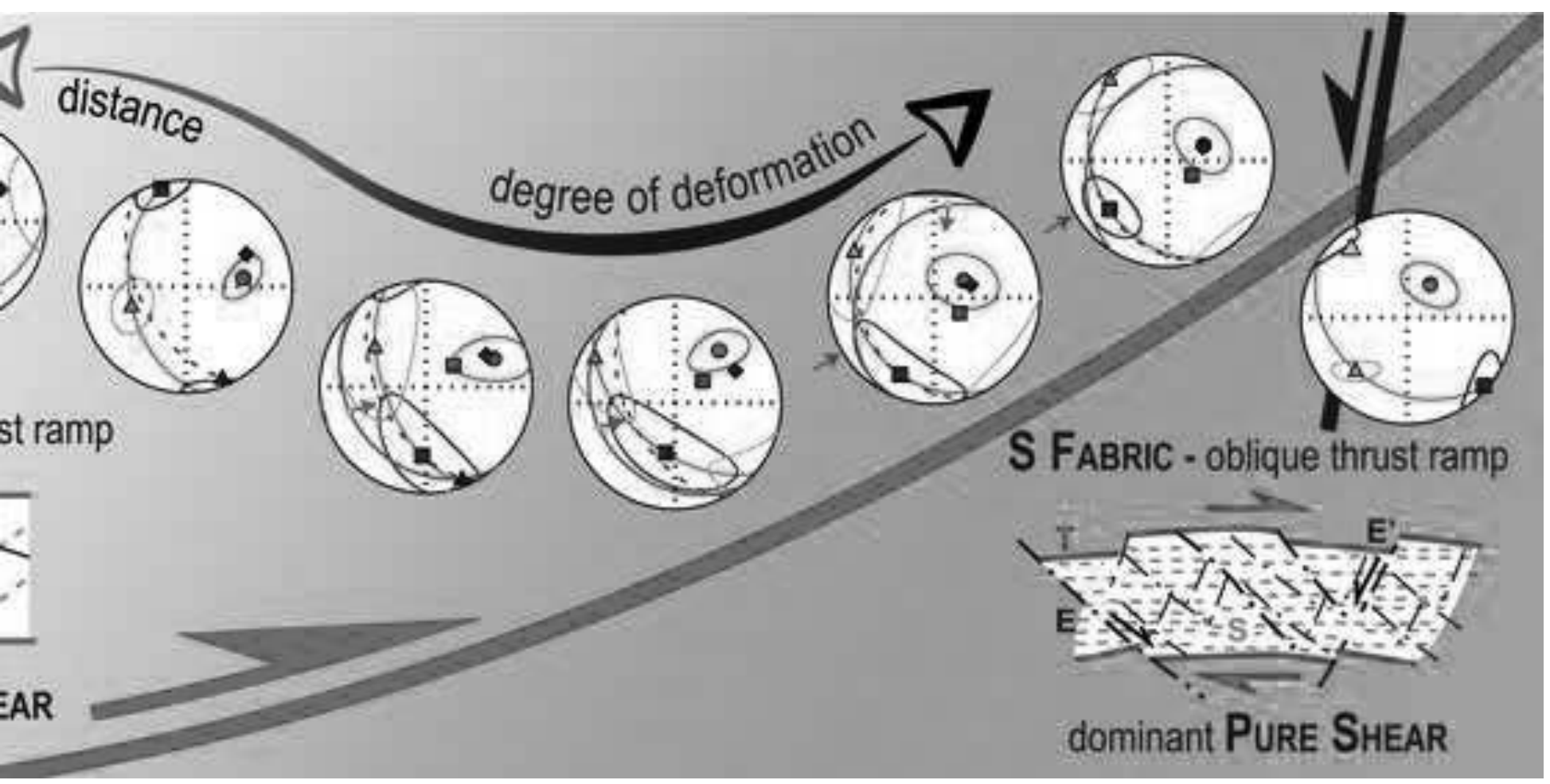


- we performed a magnetic fabric investigation on simple-to-pure-regime shear zones

- density diagrams and cluster analysis allowed distinguishing different processes

- six different fabrics were recognized depending on the intensity of deformation

- the magnetic fabric is more sensitive to the simple shear deformation 
1 Magnetic Fabric in Thrust Shear Zones: A Study from the Northern Apennines (Italy)

2

3 Sara Satolli a,b,*, Claudio Robustelli Test ${ }^{\text {b,c }}$, Dorota Staneczek ${ }^{\mathrm{d}}$, Elena Zanella ${ }^{\text {b,c }}$, Fernando

4 Calamita ${ }^{\text {a }}$, Evdokia Tema ${ }^{\text {b,c }}$

6 a Dipartimento di Ingegneria e Geologia, Università degli Studi "G. d'Annunzio" di Chieti7 Pescara, via dei Vestini 31, 66100 Chieti, Italy

8 b CIMaN-ALP, Centro Interuniversitario di Magnetismo Naturale - Alpine Laboratory of 9 Paleomagnetism, via Luigi Massa 4, 12016 Peveragno, Italy

$10{ }^{\mathrm{c}}$ Dipartimento di Scienze della Terra, Università degli Studi di Torino, via Valperga Caluso 1135,10125 Torino, Italy

$12{ }^{\mathrm{d}}$ Institute of Geophysics, Polish Academy of Sciences, Księcia Janusza 64, 01-452, Warszawa, 13 Poland

$15{ }^{*}$ Corresponding author at: Dipartimento di Ingegneria e Geologia, Università degli Studi “G.

16 d'Annunzio" di Chieti-Pescara, via dei Vestini 31, 66100 Chieti, Italy, Tel.: 00390871355

17 6427, e-mail address: sara.satolli@unich.it 


\section{ABSTRACT}

22 We present the results of an integrated structural and anisotropy of magnetic susceptibility 23 (AMS) investigation in thrust shear zones. A total of 17 sites from six localities along the

24 frontal and oblique ramp of the Olevano-Antrodoco-Sibillini thrust and back thrust (Northern

25 Apennines, Italy) were studied to investigate both magnetic fabric and structural characteristics

26 of Cretaceous to Neogene calcareous and marly rocks. In most of the sites AMS is controlled

27 by the paramagnetic minerals (prevailingly phyllosilicates). Structural analysis shows the

28 presence of SC-and S-tectonites associated to predominant simple and pure shear, respectively.

29 The combination of density diagrams and cluster analysis allowed discriminating different

30 sedimentary/tectonic overprints on a blended magnetic fabric. Six different subfabrics were

31 distinguished, related to the structural data and associated to deformation stages and regimes.

32 The magnetic foliation has a double tendency to parallelize to pressure solution cleavage (S)

33 and shear planes (C). The magnetic lineation tends to progressively align with the slip vector,

34 save for pure-shear-dominated sites at less than $15-20 \mathrm{~cm}$ from the thrust, where it aligns with

35 the transport direction. The magnetic fabric is dominated by simple shear deformation. The

36 protocol applied for AMS analysis shows a great potential to unravel blended sedimentary

37 and/or tectonic features in magnetic fabrics. AMS can be considered as a useful tool in

38 unravelling the variation of simple-pure shear deformation regime in shear zones.

40 Keywords: Magnetic fabric; Structural geology; Pure shear; Simple shear; Tectonites 


\section{Introduction}

43 Shear zones are zones of localized high deformation that can develop in any tectonic regime,

44 involving simple shear or a combination of simple and pure shear (Ramsay and Graham, 1970;

45 Ramsay, 1980; Ramsay and Huber, 1987). Tectonites in simple shear regime are characterized

46 by the association of two planar structures (Ramsay and Graham, 1970; Berthé et al., 1979;

47 Lister and Snoke, 1984): C shear planes due to localized shear strain, being parallel to the main

48 fault, and S pressure-solution cleavage due to the accumulation of finite strain (Jégouzo, 1980;

49 Ponce de Leon and Choukroune, 1980). Surfaces S and C initially form with a $45^{\circ}$ angle (SC

50 tectonites) that can gradually decrease to $0^{\circ}$ with progressive shear. At the last stage of

51 deformation, the $\mathrm{S}$ and $\mathrm{C}$ planes become sub-parallel (S tectonite). For example, S-fabric

52 characterizes oblique thrust ramps related to the transpressive reactivation of the pre-existing

53 normal faults (Pace et al., 2015).

54 Other structures associated to tectonites are calcite tension veins orthogonal to $\mathrm{S}$ that are shortened and stretched as the deformation and density of surfaces increase (Ramsay, 1980); calcite shear veins on $\mathrm{C}$, synthetic (R) and subordinated antithetic (R') shear planes, 57 respectively at ca. $15^{\circ}$ and $75^{\circ}$ with respect to C (Riedel, 1929). This geometry may be more 58 complex in sub-simple shear zones due to the presence of composed fabrics, as in the case of

59 flanking structures or folded fabrics (e.g., Passchier, 2001, Calamita et al., 2012, Pace et al., 60 2015). Both synthetic and antithetic extensional shear surfaces can be observed associated with

61 the thrust or displacing it at different stages of the deformation (e.g., Platt and Vissers, 1980;

62 Platt, 1984; Harris and Cobbold, 1985; Holdsworth et al., 2006). Moreover, conjugate 63 extensional shear planes develop along oblique thrust ramps associated with a significant 64 component of pure shear (Calamita et al., 2012; Pace et al., 2015).

65 Shear zones can occur at very different scales, but many of their aspects are scale independent, 
always showing the same characteristics (Fossen and Cavalcante, 2017). However, in an ideal

67 shear zone the strain is maximum in its central part and a progressive rotation occurs from the margin to the central part (Fossen, 2010).

69 The aim of this study is to investigate how structural deformation differences in shear zones are documented by the anisotropy of magnetic susceptibility (AMS). In fact, AMS can detect the preferred orientation of para- and ferromagnetic minerals in rocks, even when the microor macroscopic strain markers are missing. The principal magnetic susceptibility axes are related to the tectonic stress and structural features, offering important information on the sedimentary and/or tectonic setting of a studied area. The magnetic fabric of deformed rocks has been widely investigated to quantify the progressive ductile deformation, both experimentally and theoretically (e.g., Graham, 1966; Hrouda and Jezék, 1999; Borradaile and Henry, 1997; Borradaile and Hamilton, 2004; Weil and Yonkee, 2009; Parés, 2015; Almqvist and Koyi, 2018; Hrouda and Chadima, 2019). In undeformed sedimentary rocks, AMS is defined by a magnetic foliation parallel to the bedding. The minimum susceptibility axes $\left(\mathrm{k}_{3}\right)$ are vertical, while the maximum susceptibility $\left(\mathrm{k}_{1}\right)$ axes are scattered in the horizontal plane.

81 With layer-parallel shortening, a tectonic foliation develops and evolves with the increasing of deformation: first, the $\mathrm{k}_{1}$ axes become subhorizontal and perpendicular to the shortening direction, then $\mathrm{k}_{3}$ axes form a girdle parallel to the shortening direction, and finally $\mathrm{k}_{3}$ axes group subhorizontally and parallel to the shortening direction (Weil and Yonkee, 2009 and references therein). The deformation of magnetic minerals in a ductile shear zone may be ascribed to different deforming mechanisms such as grain rotation, recrystallization and plastic

87 deformation (Sidman et al., 2005; Ferré et al., 2014). Furthermore, the deformation mechanisms primarily depend on differential stress, tectonic regimes and on the mineralogical source of the AMS (e.g., Borradaile and Alford, 1988; Housen et al., 1995; Parés and van der Pluijm, 2002). 
91 We present here the results of a detailed AMS fabric investigation applied on shear zones from

923 sectors of the Northern Apennines fold-and-thrust belt. These sectors are characterized by 93 different combinations of simple and pure shear, which has been quantified through the 94 vorticity number $\mathrm{W}_{\mathrm{k}}$ (Xypolias, 2010; Calamita et al., 2012; Pace et al., 2015).

\section{Geological Setting}

97 The Triassic to Miocene sedimentary successions of the Northern Apennines were deposited 98 on the Adria paleomargin (Ciarapica and Passeri, 2002) and involved in the orogenesis during 99 the Neogene-Quaternary due to the convergence between Africa and Europe (e.g., Boccaletti 100 et al., 2005).

101 The study area is located in Pliocene outer thrust of the Northern Apennines, known as the 102 Olevano-Antrodoco-Sibillini (OAS) thrust (Fig. 1). The outer thrust shows a curved shape 103 defined by frontal NW-SE-trending and oblique NNE-SSW-trending thrust ramps to the north 104 and to the south of its apical zone, respectively. To the north, the OAS juxtaposes the Jurassic105 Cretaceous carbonate platform and pelagic sequence on the Oligocene-Miocene hemipelagic marly succession (Scaglia Cinerea, Marne con Cerrogna and Laga Fms.) belonging to the

107 Umbria-Marche domain. To the south the footwall is represented, instead, by a persistent 108 carbonate platform domain (Lazio-Abruzzi domain).

109 The Jurassic-Eocene sequence was deposited on the Adria paleomargin during the opening of 110 the Tethys ocean. Starting from the middle-late Miocene, the deformation switched from 111 extension to compression in a context of positive inversion tectonics, where pre-thrusting 112 normal faults were reactivated with different geometries (e.g., Tavarnelli et al., 2004; Butler et 113 al., 2006; Calamita et al., 2012). The southern NNE-SSW trending sector of the OAS 


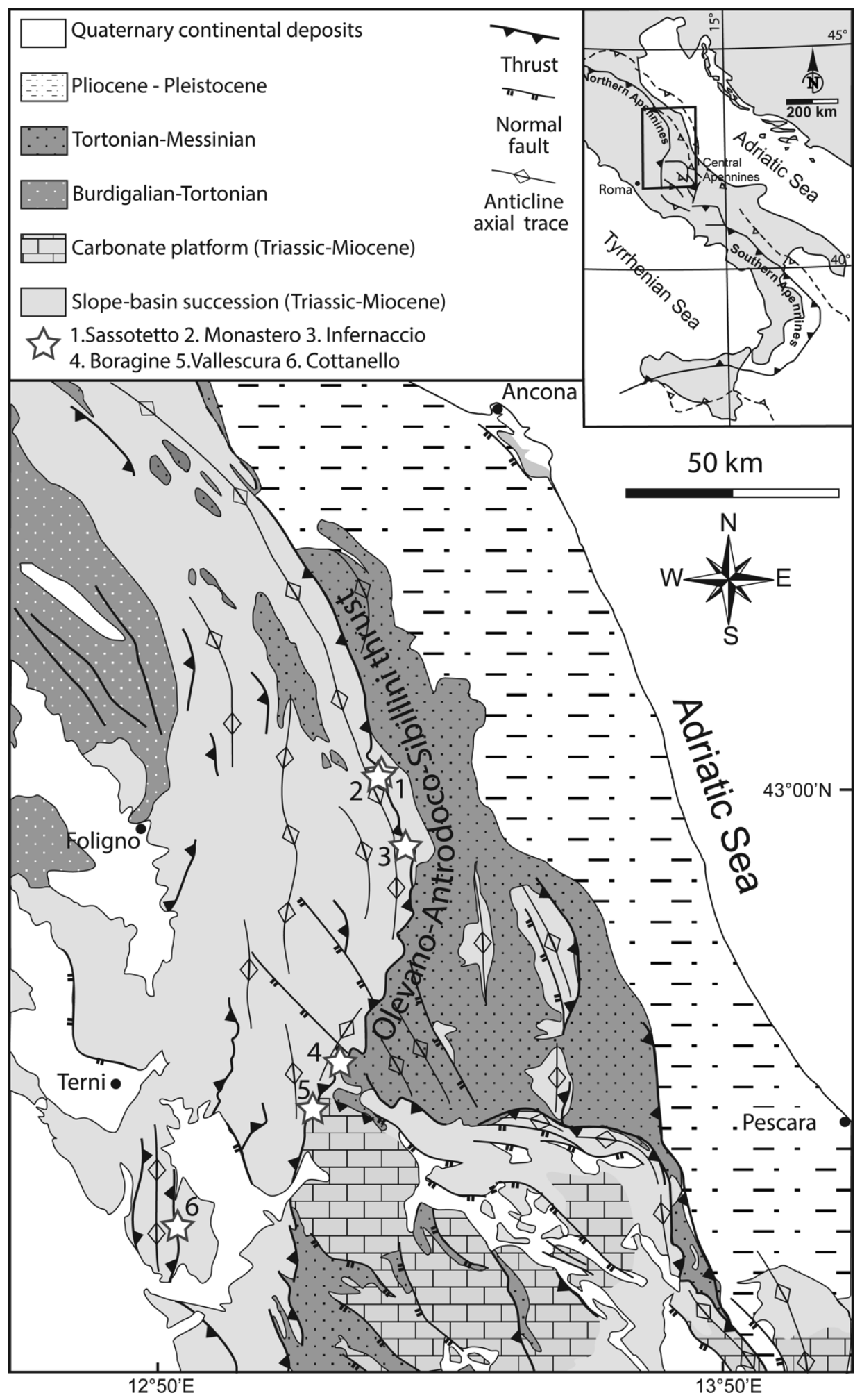

116 Figure 1: Schematic geological map of the Northern Apennines (Italy) with the studied

117 localities (white stars), modified after Calamita et al. (2012). The curve-shaped Olevano-

118 Antrodoco-Sibillini (OAS) thrust is the outer front of the Northern Apennines. 
119 reactivated the Lower Jurassic normal fault that separated the carbonate platform from the

120 pelagic domains (Ancona-Anzio fault, Castellarin et al., 1982); after its emplacement, it was

121 antiformally folded by anticlines developed in its footwall (Alberti et al., 1996).

122 During the Quaternary, post-orogenic extension, characterized by hinterland-dipping NW-SE-

123 trending normal faults with associated intermontane basins and seismicity, affected the axial

124 zone of Northern Apennines belt (Calamita et al., 2000; Di Domenica et al., 2012).

125 In the Northern Apennines, tectonites have been largely documented (Koopman, 1983;

126 Lavecchia, 1985; Calamita et al., 1987; Ghisetti, 1987; Calamita, 1991; Calamita et al., 1991,

127 2012; Alberti et al., 1996; Pierantoni, 1996; Tavarnelli, 1997, 1999). They are usually

128 associated with the outer thrust, showing different characteristics along two differently oriented

129 thrust ramps (Calamita et al., 2012).The NNE-SSW-trending oblique thrust ramp is

130 characterized by the presence of $\mathrm{S}$ tectonites, while the NW-SE-trending frontal ramp is

131 characterized by the presence of SC tectonites. The combination of simple and pure shear, thus

132 the degree of non-coaxiality of these shear zones has been quantified through the kinematic

133 vorticity number, allowing to discriminate simple-shear- and pure-shear-dominate deformation

134 (Xypolias, 2010; Calamita et al., 2012).

135 The lithologies most commonly affected by tectonites are Scaglia Rossa, Scaglia Cinerea and

136 Marne con Cerrogna. The Scaglia Rossa Fm. (Lower Turonian-middle Eocene) predominantly

137 consists in pink and red limestones and marly limestones with chert bands and nodules, and

138 average $20 \mathrm{~cm}$ bed thickness. It can be divided in 4 members: i. red/pinkish limestones with

139 dark/red chert; ii. pinkish/reddish limestones without chert; iii. marly limestones without chert;

140 iv. red marly limestones with cherts. The Cretaceous/Paleogene boundary is between facies (ii)

141 and (iii) that are also grouped in the same member in some geological maps. The non-

142 carbonatic component is represented by quartz, mica-illite, montmorillonite, hematite, 
magnetite and occasionally pyrite (Arthur and Fisher, 1977; ISPRA, 2007). After the Scaglia

144 Rossa Fm., there is a transition from pelagic to turbidite sedimentation with an increase of the

145 marly component. The Scaglia Cinerea Fm. (Upper Eocene- Lower Miocene) is represented by

146 greyish/greenish marly limestones and marls with thin bedding. It can be divided in 3 facies: $\mathrm{i}$.

147 grey/reddish limestones; ii. greyish/greenish marls; iii. greyish marls and clay. The Marne con

148 Cerrogna (Burdigalian-middle Tortonian) consists of medium to thickly bedded alternating

149 marls, calcareous marls and clay marls, intercalated with calcareous turbidites (Centamore and

150 Micarelli, 1991).

\section{Methods}

153 We sampled tectonites from different sectors of the Northern Apennines (Fig. 1) in order to

154 characterize their magnetic fabric at several localities on the frontal (Sassotetto, Monastero,

155 Infernaccio) and oblique (Boragine, Vallescura) ramps of OAS, and on a back thrust from the inner sector of the Northern Apennines (Cottanello).

\subsection{Structural analysis}

158 Structural data were collected to analyze the local trends of the main structures and the slip vector was calculated on the stereonet after measuring $\mathrm{S}$ and $\mathrm{C}$ surfaces.

160 Three localities, Sassotetto $\left(43^{\circ} 01^{\prime} 09.0^{\prime \prime} \mathrm{N}, 1^{\circ} 14^{\prime} 54.2^{\prime \prime} \mathrm{E}\right)$, Monastero $\left(43^{\circ} 03^{\prime} 30.6^{\prime} \mathrm{N}\right.$, $\left.1611^{\circ} 13^{\prime} 53.0^{\prime \prime} \mathrm{E}\right)$ and Infernaccio $\left(42^{\circ} 55^{\prime} 24.5^{\prime \prime} \mathrm{N}, 13^{\circ} 16^{\prime} 50.0^{\prime} \mathrm{E}\right)$, were selected in the frontal

162 NW-SE-trending OAS thrust. This sector is characterized by a well-developed brittle-ductile 163 shear zone, with SC tectonites of decametric thickness, mostly involving the micritic pelagic 164 limestones of the Scaglia Rossa Fm. and the marly lithologies of the Scaglia Cinerea Fm. in a 165 simple shear dominated deformation regime characterized by a vorticity number close to $1\left(\mathrm{~W}_{\mathrm{k}}\right.$ 
$=0.96-0.99 ;$ Calamita et al., 2012).

167 Two localities, Boragine $\left(42^{\circ} 29^{\prime} 30.7^{\prime \prime} \mathrm{N}, 13^{\circ} 03^{\prime} 05.5^{\prime \prime} \mathrm{E}\right)$ and Vallescura $\left(42^{\circ} 34^{\prime} 47,6^{\prime \prime} \mathrm{N}\right.$,

$\left.16813^{\circ} 08^{\prime} 21,1^{\prime \prime} \mathrm{E}\right)$ are located in the NNE-SSW-trending OAS thrust, that emplaces the pelagic

169 carbonates of Scaglia Rossa Fm. onto the marls and shales of the Marne con Cerrogna Fm..

170 Here, the shear zone is characterized by S tectonites developed in a pure shear-dominated

171 regime with a $\mathrm{W}_{\mathrm{k}}$ varying between 0.27 and 0.76 (Calamita et al., 2012; Pace et al., 2015).

172 Finally, one locality, Cottanello $\left(42^{\circ} 25^{\prime} 00,9^{\prime}\right.$ 'N $\left., 12^{\circ} 41^{\prime} 25,1^{\prime \prime} \mathrm{E}\right)$ was selected in the inner sector

173 of the Apennines, ca. $40 \mathrm{~km}$ west of the NNE-SSW-trending OAS oblique thrust ramp, in

174 proximity of a N10 trending structure known in the literature as the Sabina Fault. This feature

175 shows complex kinematics with slip vectors in three different directions: NE-SW, NNE-SSW

176 and E-W (Pierantoni, 1996). In the literature, it was interpreted as a dextral strike-slip (Alfonsi

177 et al., 1995) or transpressive fault characterized by kinematics partitioning (Pierantoni, 1996),

178 or as an east-dipping high-angle back-thrust reactivating pre-existing normal faults bounding a

179 symmetric Jurassic basin (Scisciani, 2009; Calamita et al., 2011; Di Domenica et al., 2012;

180 Pace and Calamita, 2014).

\section{$181 \quad 3.2$ Anisotropy of magnetic susceptibility}

182

\subsubsection{Sampling}

From each locality, 1 to 5 sites were sampled and studied. Both site size and sampling strategy were decided based on the homogeneity and pervasivity of the tectonic structures as well as on the outcrop conditions. However, in order to obtain significant statistical analysis, at least 10 oriented hand samples of 10-20 cm lithons were collected at each site. Sites were named accordingly to the locality (first letter: $\mathrm{S}=$ Sassotetto; $\mathrm{I}=$ Infernaccio; $\mathrm{M}=$ Monastero; $\mathrm{B}=$ Boragine; $\mathrm{V}=$ Vallescura; $\mathrm{C}=$ Cottanello), the lithology (second and third letters: $\mathrm{SR}=$ Scaglia 
Rossa Fm.; SC = Scaglia Cinerea Fm.; MC = Marne con Cerrogna Fm.) and the distance from

190 the fault plane (progressive numbers with the distance increment) or sublocality.

191 Along the frontal thrust ramp, the hanging wall was sampled at Sassotetto at ca. 15-20 m from

192 the main thrust, while the footwall was sampled at Monastero at ca. $15 \mathrm{~m}$ (MSC1) and ca. 45

$193 \mathrm{~m}$ (MSC2), and at Infernaccio at ca. $30 \mathrm{~m}$ below the main thrust.

194 From the oblique thrust ramp at Boragine and Vallescura, we sampled different levels at a

195 progressively increasing distance of $15-20 \mathrm{~cm}$ from the main thrust. In both localities, 2 sites

196 in the hanging wall into the Scaglia Rossa Fm. and 3 sites in the footwall into the Marne con

197 Cerrogna Fm. were sampled.

198 Finally, at Cottanello we sampled 3 different 1-m-wide levels located at progressively 199 increasing distance from the main fault.

200 All collected blocks were oriented in situ with a compass and an inclinometer. From each block

201 several specimens were prepared at the laboratory, weighed and centered into plastic boxes (2 $202 \mathrm{~cm} \times 2 \mathrm{~cm} \times 2 \mathrm{~cm}$ ) where they were fixed with non magnetic plasticine. A total of 327 oriented specimens was obtained from 17 sites.

\subsubsection{Laboratory Analysis and data processing}

205 For each specimen, the AMS was measured with an AGICO KLY-3 Kappabridge (sensitivity of $2 \times 10^{-8} \mathrm{SI}$ ), at the CIMaN-ALP (Centro Interuniversitario di Magnetismo Naturale - Alpine Laboratory of Paleomagnetism, Peveragno, Italy). Measurements were conducted using the manual mode (15 different directions) at the instrument's operating frequency of $875 \mathrm{~Hz}$ and

209 field intensity of $300 \mathrm{Am}^{-1}$. In order to maximize the holder correction, critical in the case of 210 samples with very low susceptibility values, we executed it on the holder, plastic box and

211 plasticine ensemble. Then, the mass magnetic susceptibility $\left(\chi_{\mathrm{m}}\right)$ was computed for each 
specimen.

213 All measurements were subjected to a quality check. Only measurements with all three F-

214 statistics of the anisotropy tests $\left(\mathrm{F}, \mathrm{F}_{12}\right.$ and $\left.\mathrm{F}_{23}\right)$ higher than 5 were accepted as reliable. $\mathrm{F}>$

2153.4817 indicates a statistically anisotropic specimen within the $95 \%$ of likelihood, and $F_{12}, F_{23}$

$216>4.2565$ allow to reject the null-hypothesis of rotational symmetry (Hrouda, 2002 and

217 references therein). In addition, few outliers characterized by $\pm 2 \sigma$ difference with respect to

218 the mean of AMS scalar parameters were excluded from further analysis.

219 On the retained specimens, the magnetic fabric was reconstructed at site level by computing 220 the AMS second rank tensor using the software ANISOFT (Chadima and Jelínek, 2008), based

221 on Jelínek statistics (Jelínek, 1977). The anisotropy tensor is represented as a tri-axial ellipsoid

$222\left(k_{1} \geq k_{2} \geq k_{3}\right)$, whose axes orientation and magnitude depends on the relative abundance of 223 mineral species and their grain orientations. Particularly, the $\mathrm{k}_{3}$ axis represents the pole of the magnetic foliation plane and the $\mathrm{k}_{1}$ direction defines the magnetic lineation. The AMS ellipsoid shape is defined by the scalar parameter $\mathrm{T}$ and can vary from oblate $(0 \leq \mathrm{T} \leq+1)$ to prolate $(-1$

$226 \leq \mathrm{T} \leq 0)($ Jelínek, 1981). The intensity of the preferred orientation of magnetic minerals, which

227 results in the eccentricity of the AMS ellipsoid, is represented by the parameter P' (Jelínek, 228 1981), called the corrected degree of anisotropy. A progressive tectonic deformation and a partial fabric overprinting due to different mineralogy behavior may result in a blended magnetic fabric (Borradaile and Jackson, 2004).

231 In order to define the presence of different subfabrics at site level, we first removed outliers

232 characterized by significant variations of $\chi_{\mathrm{m}}, \mathrm{P}^{\prime}$ and/or $\mathrm{T}$ parameters, and we then identified 233 clusters of AMS scalar parameters. When clusters were not defined by these parameters and 234 blended fabrics were clearly displayed, we applied a combination of contouring and cluster analysis on each principal axis to identify different subfabrics (Borradaile and Jackson, 2004; 
236 Borradaile and Jackson, 2010; Aubourg et al., 2010; Caricchi et al., 2016; Robustelli Test et

237 al., 2019). Subfabrics were detected computing the cluster analysis with the Stereo32 software

238 (Röller and Trepmann, 2008) and were validated using P', T and $\chi_{\mathrm{m}}$ variations. In this way, we

239 distinguished groups of specimens affected by different sedimentary or tectonic processes.

\section{Results}

\subsection{Structural data}

\subsubsection{Shear zones along frontal thrust ramps}

244 The SC tectonites show centimeter-to-decameter spaced C shear planes with calcite-bearing shear veins sub-parallel to the main thrust and centimeter-spaced S pressure solution cleavage, identifying spaced and elongated sigmoidal-shaped calcareous lithons. Millimeter- to centimeter-scale tension veins filled with calcite are perpendicular to the S foliation and lowangle synthetic R planes are also present.

249 Sassotetto and Monastero are located at the hanging wall and footwall of the same thrust shear

250 zone, respectively. Sassotetto was sampled in the Scaglia Rossa Fm. and shows C planes oriented at 250/24 and S fabric oriented at 231/57. Monastero is located in the footwall of the same thrust zone in the Scaglia Cinerea Fm. and shows C planes oriented at 232/27 and S planes oriented at 242/54. Infernaccio is also located in the footwall of the thrust shear zone

254 juxtaposing the Scaglia Rossa on the Scaglia Cinerea Fm. Here, the kinematic analysis shows

255 C planes oriented at 230/20 and S planes oriented at 254/61 (Calamita et al., 2012) while synthetic R planes are oriented at 248/09. 


\section{FRONTAL THRUST RAMP}

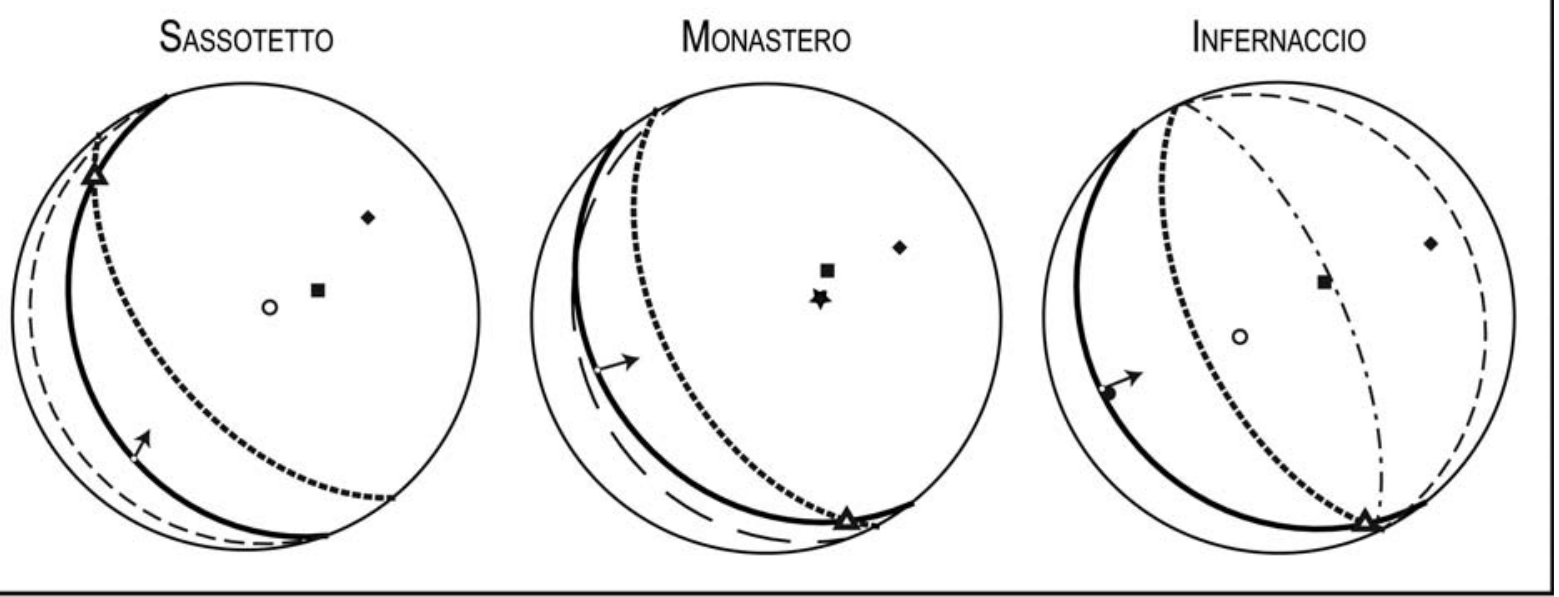

\section{OBLIQUE THRUST RAMP}
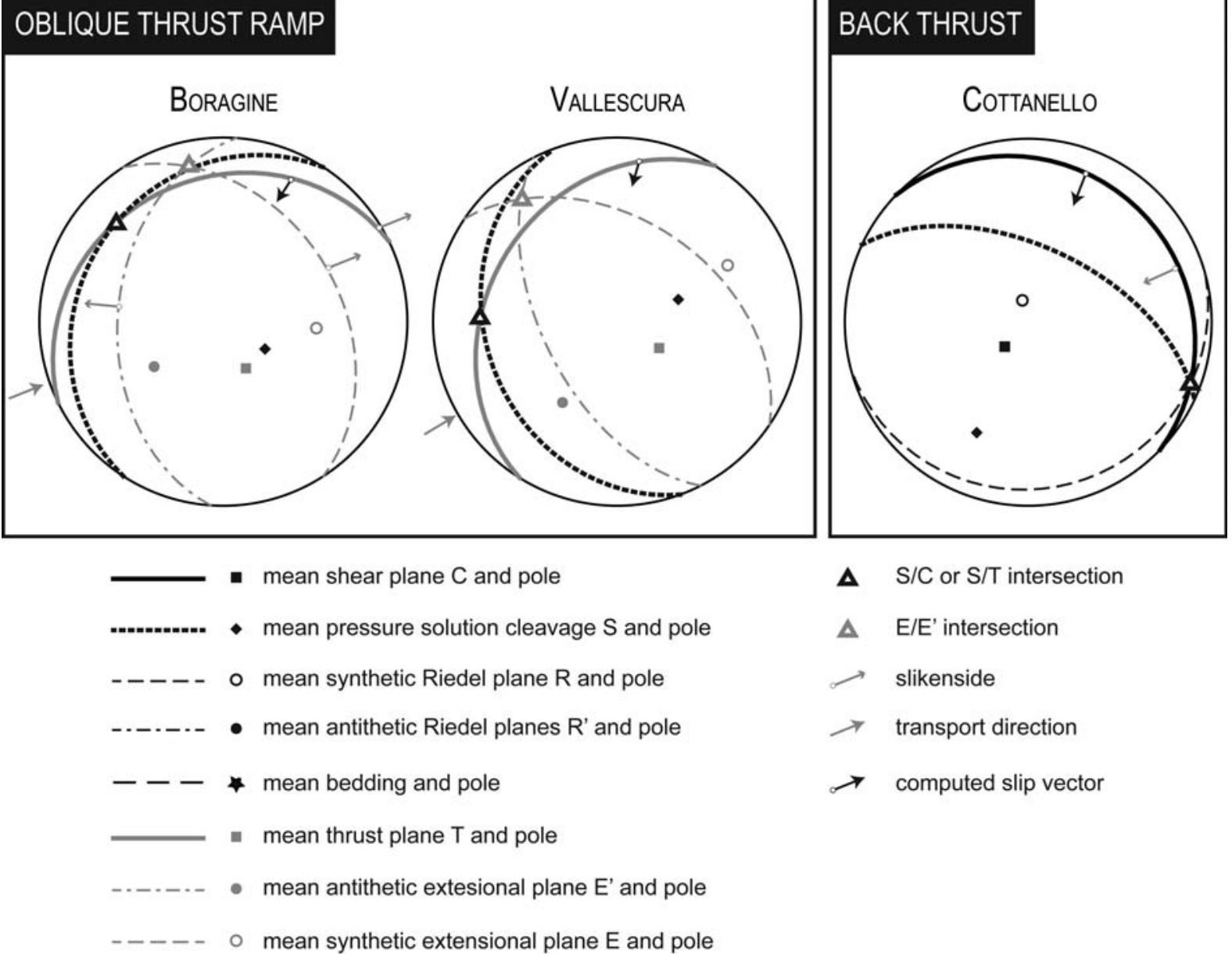

A $\mathrm{S} / \mathrm{C}$ or $\mathrm{S} / \mathrm{T}$ intersection

$\Delta \quad E / E$ ' intersection

$\longrightarrow$ slikenside

$\rightarrow$ transport direction

$\rightarrow$ computed slip vector

260 Figure 2: Summary of the structural data for each studied locality integrated with data from the literature (Calamita et al., 2012; Turtù et al., 2013; Pace et al., 2015). 
263 The S surfaces are sub-parallels to the main thrust plane, identifying marly-calcareous lens-

264 shaped lithons. The foliation is more pervasive in the marls and shales lithotypes of the Marne 265 con Cerrogna, and is decimeter-spaced in the marly/calcareous Scaglia Rossa Fm.. 266 Furthermore, synthetic and antithetic extensional structures displace the main thrust surface 267 and the associated shear zone.

268 At Boragine the thrust plane (T) is oriented 334/29 and the S surfaces are oriented 303/22, with 269 a NW-SE-trending S/T intersection. Synthetic and antithetic plane E and E' are oriented 057/37 270 and 274/42, respectively (Calamita et al., 2012; Turtù et al., 2013). At Vallescura the thrust 271 plane is oriented $302 / 30$ and the S surfaces are oriented $250 / 29$. Synthetic and antithetic planes

272 E and E' are oriented 394/44 and 243/57, respectively (Calamita et al., 2012).

273 In both localities, the N60-70 transport direction (Calamita et al., 2012) differs from the S-SSW 274 computed slip vector (Fig. 2).

\subsubsection{Back-thrust in a transpressive context}

276 Cottanello is characterized by sub-simple shear with $\mathrm{W}_{\mathrm{k}}=0.72$ (Pace et al., 2015). Here, SC 277 tectonites are well developed in the Scaglia Rossa Fm. and exposed in a quarry of the Roman 278 period (San Pietro quarry). The tectonites are characterized by centimeter-spaced C planes 279 oriented $244 / 75$ and millimeter- to centimeter-spaced S surfaces oriented $025 / 52$. Frequent 280 low-angle R synthetic planes cross the shear zone at ca. $20^{\circ}$ to the C-surfaces (Pace et al., 281 2015). The slip vector is toward S-SSW, while slickensides indicate a NE-E direction (Fig. 2). 
284 All the sampled lithologies show consistent P' and T parameters (Table 1; Fig. 3B-C). Their magnetic ellipsoids are mainly neutral to slightly oblate with mean $T=0.136 \pm 0.307$. Overall,

$286 \mathrm{P}^{\prime}$ is moderate with mean values of $\mathrm{P}^{\prime}=1.058 \pm 0.053$. Mass-susceptibility is generally low

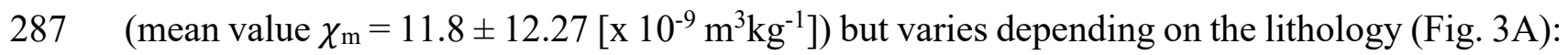
$288 \chi_{\mathrm{m}}=28.80 \pm 15.11\left[\mathrm{x} 10^{-9} \mathrm{~m}^{3} \mathrm{~kg}^{-1}\right]$ in the Scaglia Cinerea Fm.; $\chi_{\mathrm{m}}=8.22 \pm 5.61\left[\mathrm{x} 10^{-9} \mathrm{~m}^{3} \mathrm{~kg}^{-}\right.$

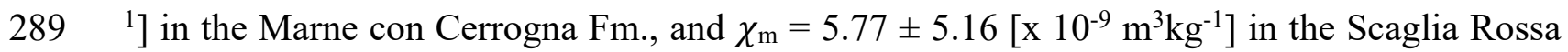
290 Fm.. The complete list of specimens and their parameters is reported in Supplementary Table $291 \quad 1$ and 2 for the specimens and at site level, respectively.

292 Those values indicate that the magnetic fabric is dominated by the contribution of paramagnetic 293 minerals such as clay minerals (Tarling and Hrouda,1993), save for two sites from the Scaglia 294 Rossa Fm. located at Boragine. In these cases, diamagnetic minerals are the main carrier of the magnetic fabric, probably also due to the high pervasivity of calcite veins. Significative low values of magnetic susceptibility in the Scaglia Rossa Fm. were also reported in previous studies (Mattei et al., 1995). The occurrence of diamagnetic phases might reveal the presence

298 of inverse fabric in those sites.

\subsubsection{AMS from the frontal thrust ramps}

300 All sites show a well-defined magnetic fabric with clustered $\mathrm{k}_{3}$ and slightly dispersed $\mathrm{k}_{1}$ and $\mathrm{k}_{2}$ axes. The magnetic foliation is mostly WSW-dipping at medium to high angle, save for site MSC2 (see Fig. 5), which shows a S-dipping sub-horizontal magnetic foliation. The shape of the ellipsoid is mainly oblate with $\mathrm{T}$ values up to 0.902 . The degree of anisotropy $\mathrm{P}^{\prime}$ is

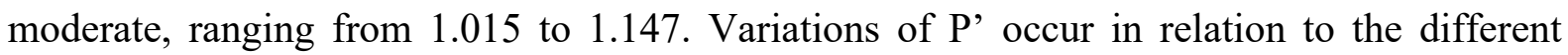
sampled lithologies and distances from the main thrust (Fig. 3B and Fig. 4A-C). 


\begin{tabular}{|c|c|c|c|c|c|c|c|c|c|c|c|c|c|c|}
\hline \multirow{3}{*}{$\begin{array}{l}\text { Locality } \\
\text { Sassotetto }\end{array}$} & \multirow{3}{*}{$\begin{array}{l}\text { Site } \\
\text { SSR1 }\end{array}$} & \multirow{3}{*}{ Stage } & \multirow{3}{*}{$\begin{array}{c}\mathbf{n} / \mathbf{N} \\
16 / 20\end{array}$} & \multirow{3}{*}{$\begin{array}{c}\begin{array}{c}\chi \mathrm{m}( \pm \sigma) \\
\left(\times 10^{-9} \mathrm{~m}^{3} \mathbf{k g}^{-1}\right)\end{array} \\
11.16 \pm 5.19\end{array}$} & \multirow{3}{*}{$\begin{array}{c}\mathbf{P}^{\prime} \\
1,040\end{array}$} & \multirow{3}{*}{$\begin{array}{c}\mathbf{T} \\
0,785\end{array}$} & \multicolumn{4}{|c|}{$k_{1}$} & \multicolumn{4}{|c|}{$\mathbf{k}_{3}$} \\
\hline & & & & & & & \multirow{2}{*}{$\begin{array}{c}\text { D } \\
295\end{array}$} & \multirow{2}{*}{$\begin{array}{c}\text { I } \\
32\end{array}$} & \multicolumn{2}{|c|}{$\begin{array}{l}95 \% \text { conf. } \\
\text { angles }\end{array}$} & \multirow{2}{*}{$\begin{array}{c}\text { D } \\
47\end{array}$} & \multirow{2}{*}{$\begin{array}{c}\text { I } \\
31\end{array}$} & \multicolumn{2}{|c|}{$\begin{array}{l}95 \% \text { conf. } \\
\text { angles }\end{array}$} \\
\hline & & & & & & & & & 52,1 & 18,3 & & & 21,1 & 11,6 \\
\hline & SSR1-SF1 & $E$ & $10 / 16$ & $12.71 \pm 5.76$ & 1,030 & 0,671 & 191 & 50 & 56,7 & 22,9 & 40 & 36 & 26,8 & 12,9 \\
\hline & SSR1-SF2 & C & $6 / 16$ & $8.56 \pm 2.86$ & 1,061 & 0,386 & 304 & 29 & 18,6 & 8,8 & 51 & 28 & 13,3 & 8,6 \\
\hline \multirow[t]{6}{*}{ Monastero } & MSC1 & & $19 / 20$ & $39.65 \pm 21.54$ & 1,021 & 0,613 & 342 & 5 & 35,1 & 13,5 & 76 & 39 & 18,6 & 12,1 \\
\hline & MSC1-SF1 & C & $8 / 19$ & $17.20 \pm 4.45$ & 1,021 & 0,903 & 161 & 2,3 & 77,5 & 12,0 & 70 & 32 & 14,4 & 8,9 \\
\hline & MSC1-SF2 & C & $11 / 19$ & $55.98 \pm 11.19$ & 1,023 & 0,465 & 346 & 6 & 19,2 & 13,2 & 82 & 45 & 20,2 & 10,7 \\
\hline & MSC2 & & $19 / 19$ & $24.69 \pm 2.66$ & 1,017 & 0,648 & 133 & 13 & 59,4 & 13,0 & 1 & 71 & 22,2 & 13,8 \\
\hline & MSC2-SF1 & A & $10 / 19$ & $24.12 \pm 1.91$ & 1,019 & 0,158 & 100 & 1 & 31,8 & 12,9 & 8 & 77 & 17,0 & 11,4 \\
\hline & MSC2-SF2 & B & $9 / 19$ & $25.32 \pm 3.39$ & 1,020 & 0,052 & 169 & 22 & 28,5 & 14,2 & 351 & 68 & 32,5 & 14,2 \\
\hline \multirow[t]{3}{*}{ Infernaccio } & ISC1 & & $19 / 21$ & $22.07 \pm 7.02$ & 1,032 & 0,856 & 212 & 50 & 75,1 & 24,4 & 76 & 32 & 30,1 & 24,6 \\
\hline & ISC1-SF1 & $D$ & $14 / 19$ & $18.63 \pm 2.86$ & 1,014 & 0,479 & 183 & 35 & 53,3 & 21,6 & 68 & 31 & 33,8 & 14,9 \\
\hline & ISC1-SF2 & $\mathrm{E}$ & $5 / 19$ & $31.71 \pm 6.10$ & 1,117 & 0,657 & 297 & 59 & 17,9 & 7,7 & 79 & 25 & 18,7 & 7,6 \\
\hline \multirow[t]{9}{*}{ Monte Boragine } & BSR2 & $\mathrm{F}^{*}$ & $10 / 15$ & $-2.03 \pm 0.98$ & 1,076 & $-0,351$ & 319 & 59 & 68,7 & 18,1 & 180 & 25 & 31,9 & 16,0 \\
\hline & BSR1 & $\mathrm{F}^{*}$ & $10 / 19$ & $-3.33 \pm 1.81$ & 1,027 & $-0,656$ & 169 & 80 & 70,0 & 31,0 & 9 & 10 & 43,3 & 23,9 \\
\hline & $\mathrm{BMC1}$ & $\mathrm{E}^{\prime \prime}$ & $8 / 12$ & $2.52 \pm 1.94$ & 1,055 & 0,147 & 250 & 46 & 59,9 & 27,9 & 4 & 21 & 52,9 & 20,8 \\
\hline & BMC2 & & $13 / 16$ & $9.83 \pm 6.33$ & 1,032 & 0,593 & 243 & 13 & 43,6 & 17,3 & 128 & 61 & 25,7 & 17,3 \\
\hline & BMC2-SF1 & $E$ or $E^{\prime \prime}$ & $6 / 13$ & $6.44 \pm 2.28$ & 1,027 & 0,175 & 35 & 6 & 37,0 & 23,4 & 134 & 57 & 31,3 & 14,7 \\
\hline & BMC2-SF2 & $\mathrm{D}^{\prime \prime}$ & $7 / 13$ & $12.74 \pm 7.37$ & 1,040 & 0,410 & 266 & 23 & 30,8 & 18,2 & 121 & 63 & 22,4 & 14,2 \\
\hline & BMC3 & & $15 / 21$ & $1.05 \pm 2.96$ & 1,121 & $-0,037$ & 201 & 21 & 44,2 & 24,5 & 9 & 69 & 59,4 & 23,6 \\
\hline & BMC3-SF1 & $E$ or $E^{\prime \prime}$ & $8 / 15$ & $3.34 \pm 1.96$ & 1,035 & $-0,225$ & 211 & 1 & 49,7 & 20,5 & 304 & 72 & 45,3 & 28,5 \\
\hline & BMC3-SF2 & $D^{*}$ & $7 / 15$ & $-1.56 \pm 1.00$ & 1,080 & 0,071 & 197 & 29 & 34,2 & 19,9 & 29 & 61 & 54,6 & 15,2 \\
\hline \multirow[t]{13}{*}{ Valle Scura } & VSR2 & & $19 / 21$ & $7.23 \pm 1.88$ & 1,022 & 0,010 & 207 & 25 & 32,2 & 17,8 & 31 & 65 & 35,3 & 16,6 \\
\hline & VSR2-SF1 & $E^{\prime \prime}$ & $14 / 19$ & $7.12 \pm 1.80$ & 1,027 & $-0,383$ & 211 & 25 & 23,3 & 16,7 & 28 & 65 & 43,5 & 15,2 \\
\hline & VSR2-SF2 & $\mathrm{F}$ & $5 / 19$ & $7.52 \pm 2.29$ & 1,020 & $-0,134$ & 132 & 4 & 23,0 & 12,1 & 35 & 59 & 22,7 & 15,6 \\
\hline & VSR1 & $\mathrm{E}^{\prime \prime}$ & $23 / 24$ & $9.29 \pm 2.17$ & 1,039 & 0,091 & 230 & 28 & 24,3 & 18,0 & 67 & 61 & 24,3 & 18,0 \\
\hline & VMC1 & & $18 / 21$ & $8.56 \pm 3.56$ & 1,015 & 0,529 & 263 & 21 & 68,5 & 14,8 & 29 & 57 & 33,5 & 18,7 \\
\hline & VMC1-SF1 & $E^{\prime \prime}$ & $10 / 18$ & $8.16 \pm 2.22$ & 1,020 & $-0,346$ & 227 & 26 & 22,5 & 18,6 & 1 & 55 & 45,1 & 21,6 \\
\hline & VMC1-SF2 & $\mathrm{F}$ & $8 / 18$ & $9.07 \pm 4.89$ & 1,023 & $-0,361$ & 303 & 5 & 28,3 & 9,6 & 38 & 42 & 46,0 & 10,3 \\
\hline & VCM2 & & $19 / 21$ & $12.25 \pm 2.37$ & 1,024 & 0,406 & 234 & 21 & 49,0 & 15,8 & 37 & 68 & 22,7 & 15,8 \\
\hline & VMC2-SF1 & $\mathrm{D}^{\prime \prime}$ & $9 / 19$ & $12.25 \pm 2.37$ & 1,032 & $-0,004$ & 253 & 19 & 11,6 & 10,5 & 43 & 68 & 28,2 & 8,7 \\
\hline & VMC2-SF2 & $E$ & $10 / 19$ & $12.42 \pm 1.51$ & 1,020 & 0,186 & 191 & 20 & 25,6 & 14,1 & 28 & 69 & 26,8 & 14,9 \\
\hline & VCM3 & & $18 / 21$ & $11.56 \pm 3.62$ & 1,022 & 0,442 & 204 & 22 & 44,0 & 20,6 & 60 & 64 & 28,3 & 20,1 \\
\hline & VMC3-SF1 & $\mathrm{D}^{\prime \prime}$ & $8 / 18$ & $11.44 \pm 3.24$ & 1,025 & 0,120 & 244 & 38 & 30,4 & 17,3 & 64 & 53 & 23,6 & 21,8 \\
\hline & VMC3-SF2 & $\mathrm{E}$ & $10 / 18$ & $12.18 \pm 4.37$ & 1,025 & 0,181 & 185 & 12 & 21,0 & 15,1 & 37 & 77 & 25,9 & 16,3 \\
\hline Cottanello & CSR1 & & $13 / 15$ & $2.97 \pm 1.21$ & 1,025 & $-0,056$ & 317 & 35 & 50,4 & 26,9 & 204 & 29 & 39,4 & 26,3 \\
\hline & CSR1-SF1 & $D$ & $6 / 13$ & $2.4 \pm 1.37$ & 1,039 & 0,113 & 325 & 42 & 53,5 & 22,8 & 188 & 39 & 36,8 & 21,3 \\
\hline & CSR1-SF2 & C & $7 / 13$ & $3.47 \pm 0.86$ & 1,019 & 0,097 & 312 & 17 & 51,2 & 11,4 & 221 & 5 & 30,5 & 11,4 \\
\hline & CSR2 & & $16 / 22$ & $5.72 \pm 2.79$ & 1,026 & 0,058 & 329 & 22 & 47,5 & 25,1 & 167 & 67 & 47,6 & 23,0 \\
\hline & CSR2-SF1 & $E$ & $8 / 16$ & $5.91 \pm 2.78$ & 1,045 & 0,222 & 13 & 40 & 22,2 & 13,5 & 188 & 50 & 14,6 & 13,0 \\
\hline & CSR2-SF2 & C & $8 / 16$ & $5.52 \pm 2.97$ & 1,038 & 0,329 & 324 & 4 & 32,8 & 12,9 & 60 & 57 & 27,4 & 13,6 \\
\hline & CSR3 & & $15 / 20$ & $6.76 \pm 4.20$ & 1,042 & 0,453 & 12 & 18 & 56,0 & 26,6 & 228 & 68 & 26,8 & 10,8 \\
\hline & CSR3-SF1 & $E$ & $9 / 15$ & $5.80 \pm 4.30$ & 1,049 & $-0,026$ & 20 & 16 & 36,0 & 26,5 & 240 & 69 & 26,8 & 14,6 \\
\hline & CSR3-SF2 & C & $6 / 15$ & $8.19 \pm 3.97$ & 1,042 & 0,395 & 308 & 1 & 37,4 & 8,0 & 217 & 61 & 20,9 & 4,8 \\
\hline
\end{tabular}


307 Table 1: Summary of the anisotropy of magnetic susceptibility data at site level.

308 Columns: Locality; Site; Stage = degree of deformation from sedimentary fabric (A) to latest

309 tectonic event $(\mathrm{F}),(*)$ inverse fabric and $(/ /)$ tectonic fabric parallel to the transport direction;

$310 \mathrm{n} / \mathrm{N}=$ number of specimens accepted/number of specimens measured; $\chi_{\mathrm{m}}=$ mean mass magnetic

311 susceptibility $\left(10^{-9} \mathrm{~m}^{3} \mathrm{~kg}^{-1}\right)$ and its standard deviation; $\mathrm{P}^{\prime}=$ corrected anisotropy degree; $\mathrm{T}=$

312 shape parameter; $\mathrm{D}=$ declination $\left(^{\circ}\right), \mathrm{I}=$ inclination $\left(^{\circ}\right)$ and $95 \%$ confidence angle $\left(^{\circ}\right)$ of the

313 principal magnetic susceptibility axes $\mathrm{k}_{1}$ and $\mathrm{k}_{3}$, respectively.

315 The SC tectonites at Sassotetto (Fig. 5) show an oblate magnetic fabric $\mathrm{T}=0.785 \pm 0.340$. The

316 magnetic foliation is SW-dipping and steeply inclined. Two different subfabrics have been

317 detected: i. subfabric 1 is characterized by a lower anisotropy degree and higher $\chi_{\mathrm{m}}$ (Table 1;

318 Fig.4A). The magnetic fabric is slightly oblate with a N-S trending magnetic lineation; ii.

319 subfabric 2 , characterized by higher P' and lower $\chi_{\mathrm{m}}$, shows an oblate fabric with a sub-

320 horizontal NW-SE-trending $\mathrm{k}_{1}$ axis.

321 Both sites from Monastero (Fig. 5) show two overlapping magnetic fabrics. Site MSC1 is

322 characterized by a steep WSW-dipping magnetic foliation and $\mathrm{k}_{1}$ axis N-S trending. The plot

323 of $\chi_{\mathrm{m}}$ versus $\mathrm{P}^{\prime}$ reveals two clusters corresponding to two subfabrics with consistent magnetic

324 foliation and lineation (Fig. 4B, Fig. 5): i. subfabric 1 (MSC1-Sf1) is characterized by lower

325 P' and $\chi_{\mathrm{m}}$ values, and a higher dispersion of $\mathrm{k}_{1}$ and $\mathrm{k}_{2}$ axes on the magnetic foliation plane; ii.

326 instead, subfabric 2 (MSC1-Sf2) shows well grouped axes. 

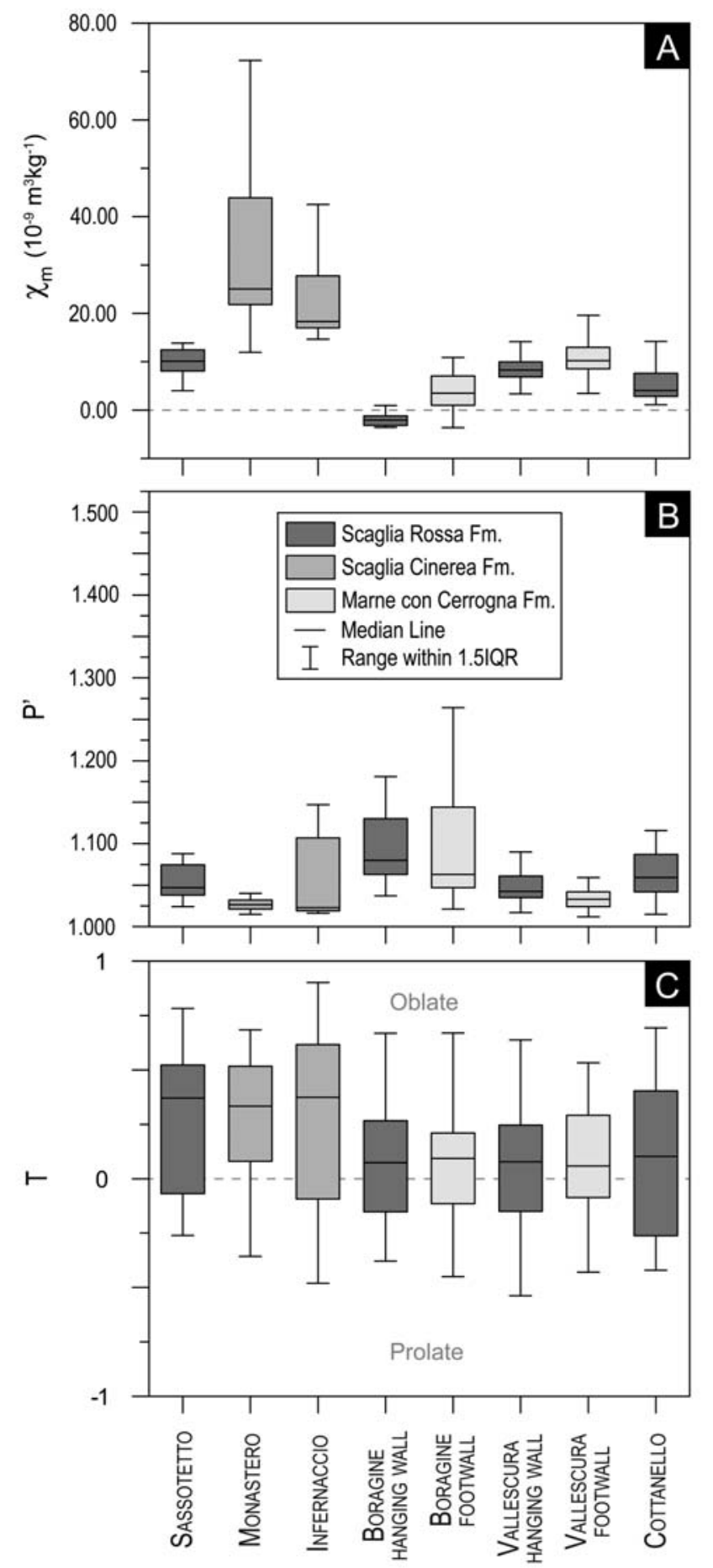

328 Figure 3: Box-and-whisker plots of the a) mass magnetic susceptibility $\left(\chi_{\mathrm{m}}\right)$, b) corrected

329 anisotropy degree (P') and c) shape parameter (T) for the studied localities. Central boxes 330 include values between the lower and upper quartiles. Different gray shades correspond to 331 different lithologies. 


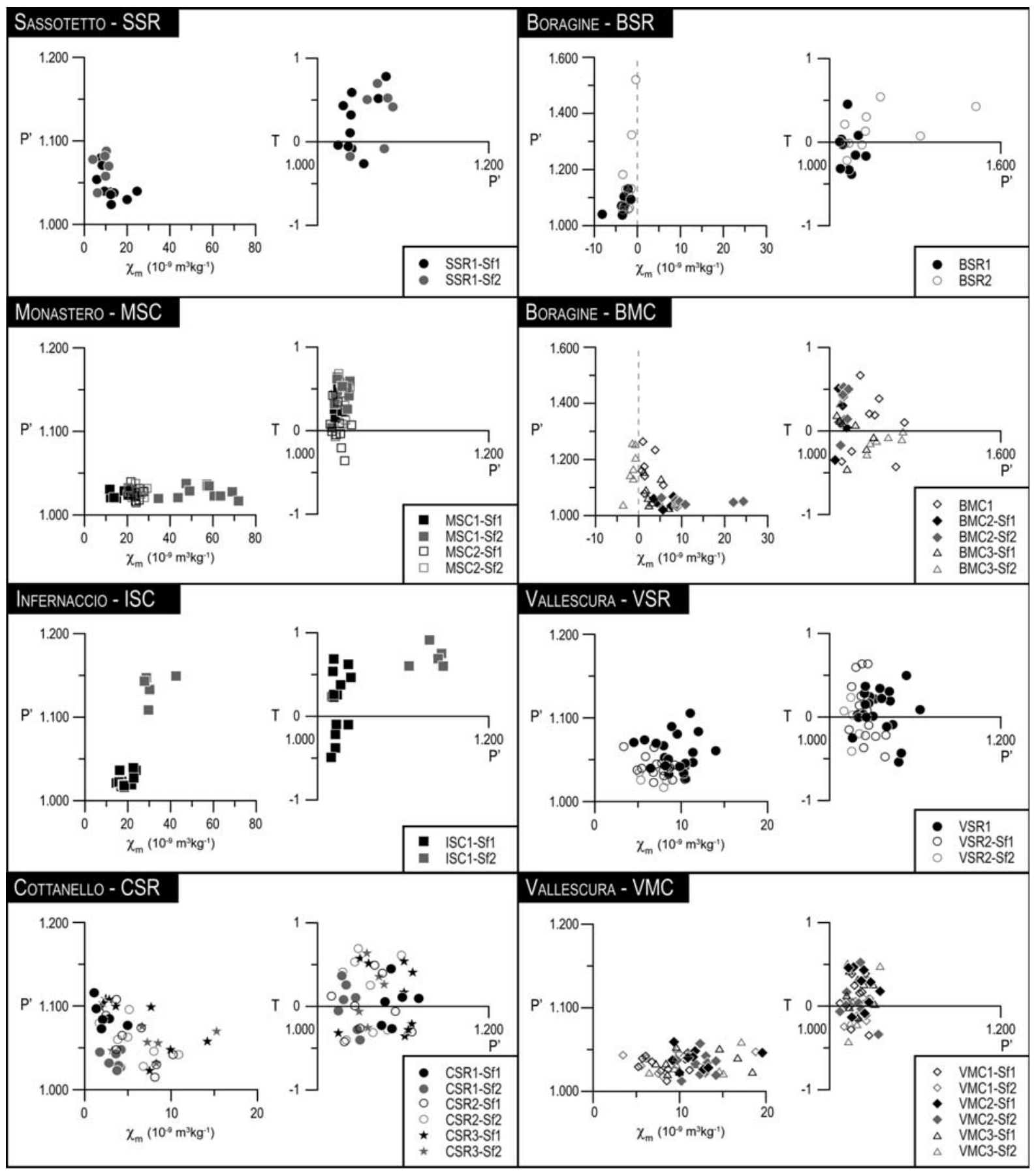

334 Figure 4: Corrected anisotropy degree (P') vs. mass susceptibility $\left(\chi_{\mathrm{m}}\right)$ and shape parameter

335 (T) vs. corrected anisotropy degree (P') plots for the various localities. Different symbols 336 correspond to different lithologies: circles and stars for Scaglia Rossa Fm., squares for Scaglia

337 Cinerea Fm. and lozenges and triangles for Marne con Cerrogna Fm. 
339 Site MSC2 displays a sub-horizontal S-dipping magnetic foliation. Here, the two subfabrics

340 (see MSC2-Sf1 and MSC2-Sf2 in Fig. 5) show consistent $\mathrm{k}_{3}$ but different mean $\mathrm{k}_{1}$ and $\mathrm{k}_{2}$

341 axes orientations. The different axes orientation is associated with variations in shape

342 parameter $(\mathrm{T})$. Subfabric 1 is characterized by a slightly oblate ellipsoid $(\mathrm{T}=0.158 \pm 0.230)$

343 and a sub-horizontal E-W trending magnetic lineation, while sufabric 2, showing a N-S

344 trending magneticlineation, is neutral with $\mathrm{T}=0.052 \pm 0.240$.

345 Infernaccio shows the superposition of two subfabrics (see ISC1-Sf1 and ISC1-Sf2 in Fig. 5

346 and Fig. 4C) that differ in terms of AMS scalar parameters and $\mathrm{k}_{1}$ axes orientations: i. subfabric

3471 displays a neutral fabric with dispersed $\mathrm{k}_{1}$ and $\mathrm{k}_{2}$ axes and a sub-horizontal magnetic lineation

348 mainly N-S trending, lower P' values and high variability of shape parameter ranging from -

3490.481 to 0.678 ; ii. subfabric 2 is characterized by well grouped axes with E-W trending $\mathrm{k}_{1}$, and 350 strongly oblate fabric and high anisotropy degree.

\subsubsection{AMS from the oblique thrust ramp}

352 The magnetic fabric is represented by a blended AMS fabric, with mainly neutral to slightly oblate magnetic ellipsoid $(\mathrm{T}=0.077 \pm 0.269)($ Table $1 ;$ Fig. 3$) . \mathrm{k}_{3}$ axes are mostly grouped, while $\mathrm{k}_{1}$ and $\mathrm{k}_{2}$ are dispersed on the magnetic foliation. The anisotropy degree is moderate with mean value of $\mathrm{P}^{\prime}=1.066 \pm 0.064 . \chi_{\mathrm{m}}$ values significantly vary between localities. This in turn determines the differences in magnetic fabric configuration.

357 Boragine is characterized by significative changes of $\chi_{\mathrm{m}}$ values between lithologies. Specimens from Scaglia Rossa Fm. (sites BSR1 and BSR2 in Fig. 6 and Fig. 4E) are mainly diamagnetic, with $\chi_{\mathrm{m}}=-1.73 \pm 2.60\left[\mathrm{x} 10^{-9} \mathrm{~m}^{3} \mathrm{~kg}^{-1}\right]$. The three sites from Marne con Cerrogna Fm. show

360 higher values, with a maximum value of $24.35\left[\mathrm{x} 10^{-9} \mathrm{~m}^{3} \mathrm{~kg}^{-1}\right]$. This significantly affects the configuration of the AMS fabric in this location. 


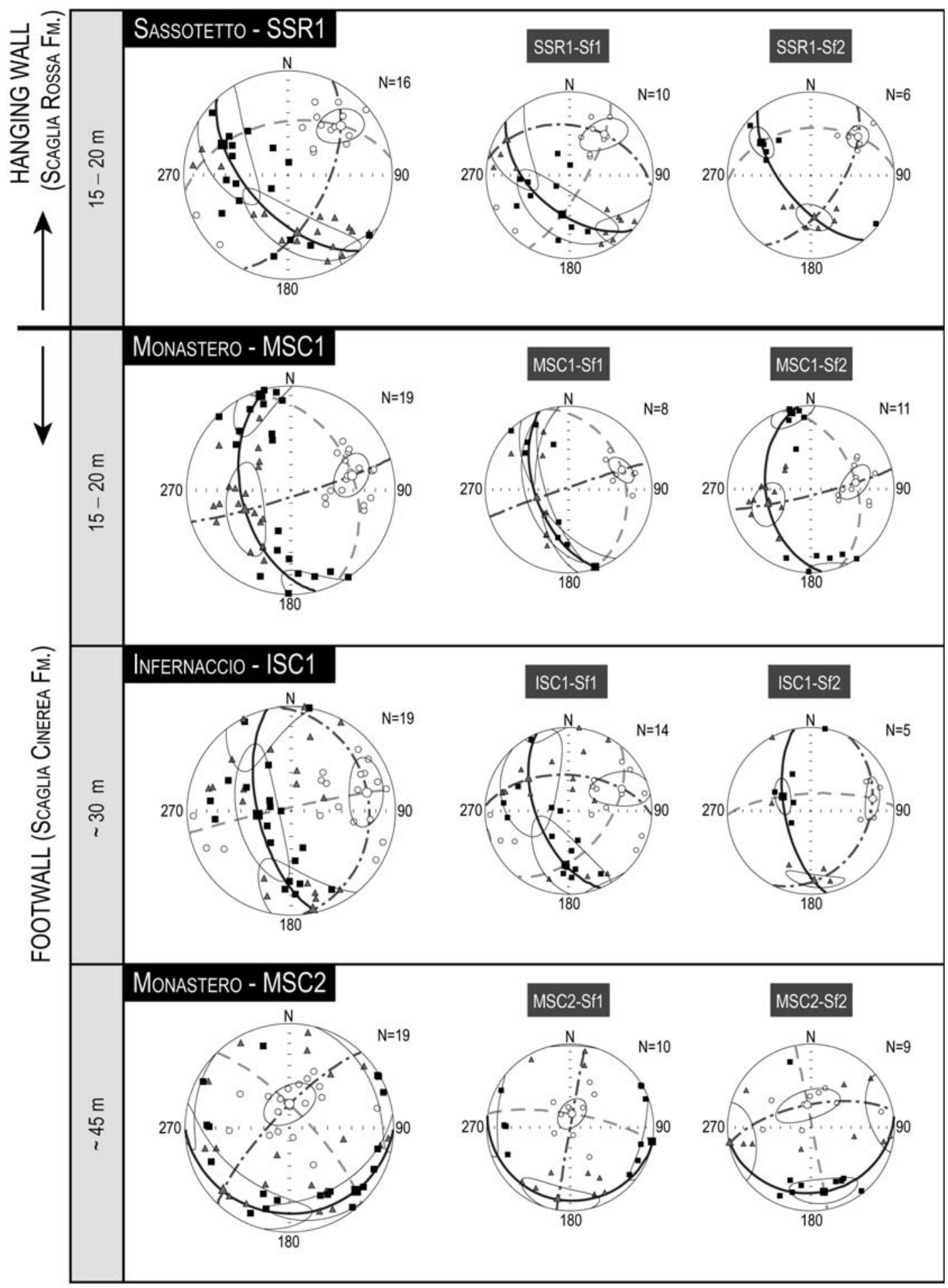


365 Figure 5 (previous page): Magnetic fabric from the frontal thrust ramp at Sassotetto,

366 Monastero (sites MSC1 and MSC2) and Infernaccio. Equal area projections in geographic

367 coordinates of the principal magnetic susceptibility axes at site level (left) and relative

368 subfabrics (middle and right).

369

370 Sites BSR1 and BSR2, located above the main thrust, display an E-W-trending subvertical

371 magnetic foliation with dispersed $\mathrm{k}_{1}$ and $\mathrm{k}_{2}$ axes (Fig. 6). Despite higher and positive $\chi_{\mathrm{m}}$ values

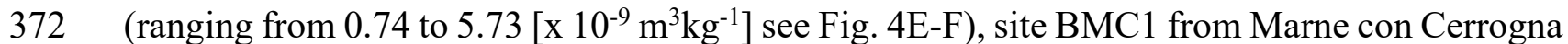

373 shows a similar blended fabric with a sub-vertical E-W-trending magnetic foliation. Here,

374 specimens display $\mathrm{k}_{1}$ axes E-W to SW-NE trending at medium angles.

375 The other two sites from Marne con Cerrogna Fm., BMC2 and BMC3, are characterized by a

376 fabric with a sub-horizontal magnetic foliation. The ellipsoid shapes are slightly oblate and

377 prolate, respectively. The site BMC2 might be characterized by the presence of two neutral

378 subfabrics with the same orientation of the magnetic foliation. The $\mathrm{k}_{1}$ axes form an angle of

379 about $122^{\circ}$ between subfabrics. Instead, at site BMC3 specimens with negative $\chi_{\mathrm{m}}$ values

380 (BMC3-Sf1 in Fig. 6) define a prolate subfabric characterized by higher P'.

381 All sites from Vallescura have a consistent magnetic fabric (Fig. 7). Overall, the AMS fabric

382 shows a magnetic foliation SW-dipping at low angle with slightly dispersed $\mathrm{k}_{1}$ and $\mathrm{k}_{2}$ axes.

383 The $\mathrm{P}^{\prime}$ values are moderate $\left(\mathrm{P}^{\prime}=1.040 \pm 0.017\right)$ and the shape parameter is slightly oblate with

384 mean values $\mathrm{T}=0.283 \pm 0.264$ (Fig. 4G-H).

385 Two different subfabrics are detected at sites level: i. subfabric 1, characterized by a magnetic

386 foliation SW-dipping and sub-horizontal SW-NE to WSW-ENE trending magnetic lineation;

387 ii. subfabric 2 shows a sub-horizontal magnetic foliation and NW-SE to N-S trending $\mathrm{k}_{1}$ axes. 


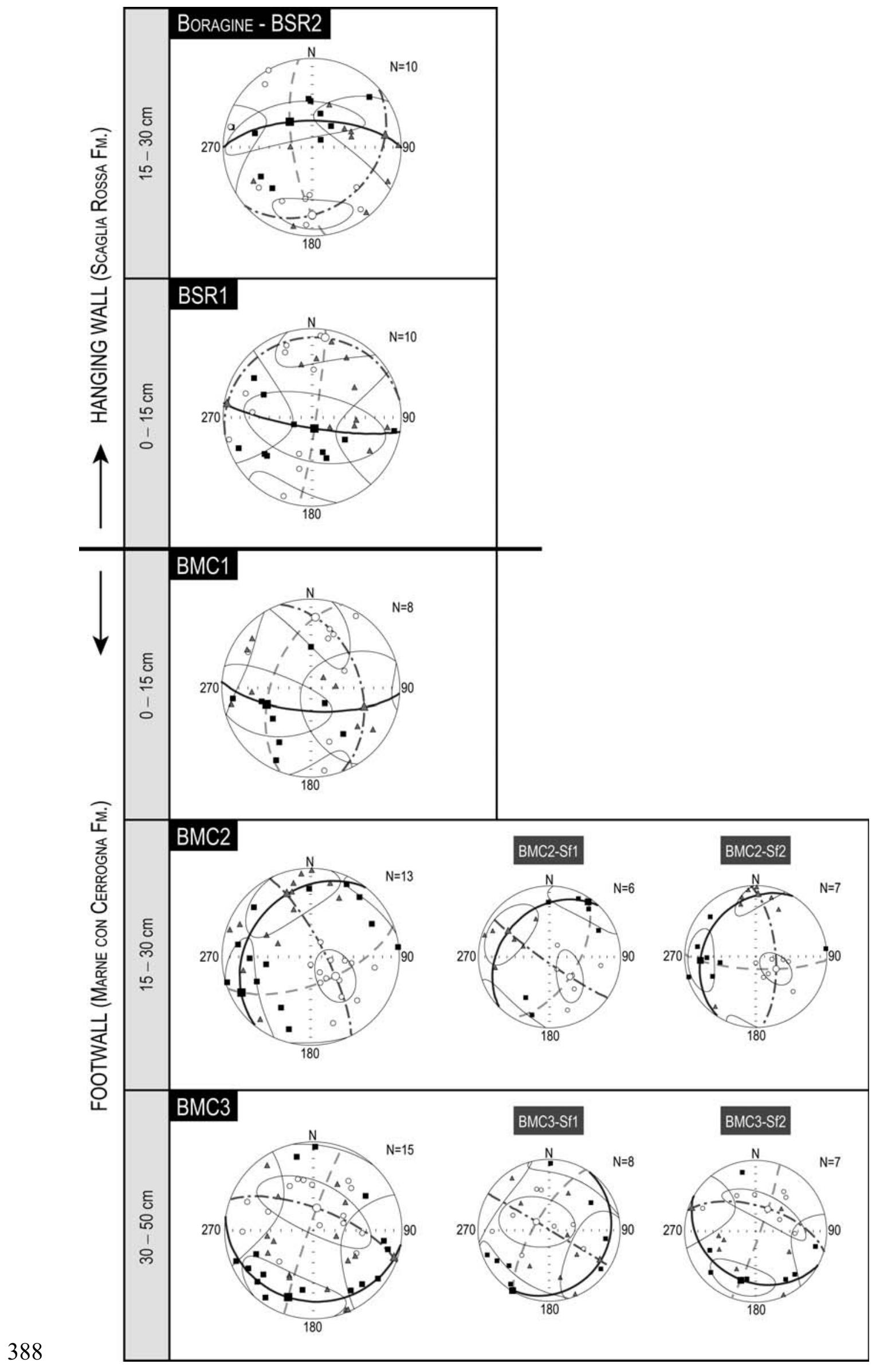


389 Figure 6 (previous page): Magnetic fabric from the oblique thrust ramp at Boragine. Equal 390 area projections in geographic coordinates of the principal magnetic susceptibility axes at site

391 level (left) and relative subfabrics when detected (middle and right). Legend as in Figure 5.

392

393 The subfabric 1 dominates the main fabric. In fact, it strongly affects the orientation of both

394 magnetic foliation and lineation. Furthermore, $\mathrm{k}_{1}$ and $\mathrm{k}_{3}$ axes show counterclockwise (CCW)

395 and clockwise $(\mathrm{CW})$ rotations when the distance from the main thrust increases, in the hanging 396 wall and footwall respectively. Instead, subfabric 2 shows consistent configuration close to the 397 main thrust with a NW-SE-trending magnetic lineation. In the footwall, $\mathrm{k}_{1}$ rotates by $116^{\circ}$ $398 \mathrm{CCW}$ passing from site $\mathrm{VMC} 1$ to $\mathrm{VMC} 2$, thus when increasing the distance from the thrust.

\subsubsection{AMS from back-thrust}

400 All sites show a magnetic fabric characterized by slightly clustered $\mathrm{k}_{3}$ axes. The $\mathrm{k}_{1}$ and $\mathrm{k}_{2}$ axes

401 are dispersed on the $\mathrm{N}$ to NNE-dipping magnetic foliation. The low to moderate $\chi_{\mathrm{m}}$ (mean

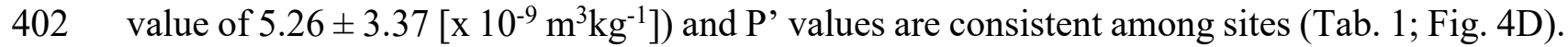
403 Shape parameters change from mainly oblate at site CSR3 to slightly prolate at sites CSR1. At 404 the same time, the magnetic foliation shifts from sub-horizontal to sub-vertical (Fig. 8).

405 In addition, all sites reveal the presence of two subfabrics: i. subfabric 1 showing a slightly 406 inclined magnetic lineation NNW to NE trending; ii. subfabric 2 characterized by a NW-SE407 trending sub-horizontal magnetic lineation. Similar fabric has been previously documented in 408 this area (Mattei et al., 1995). 


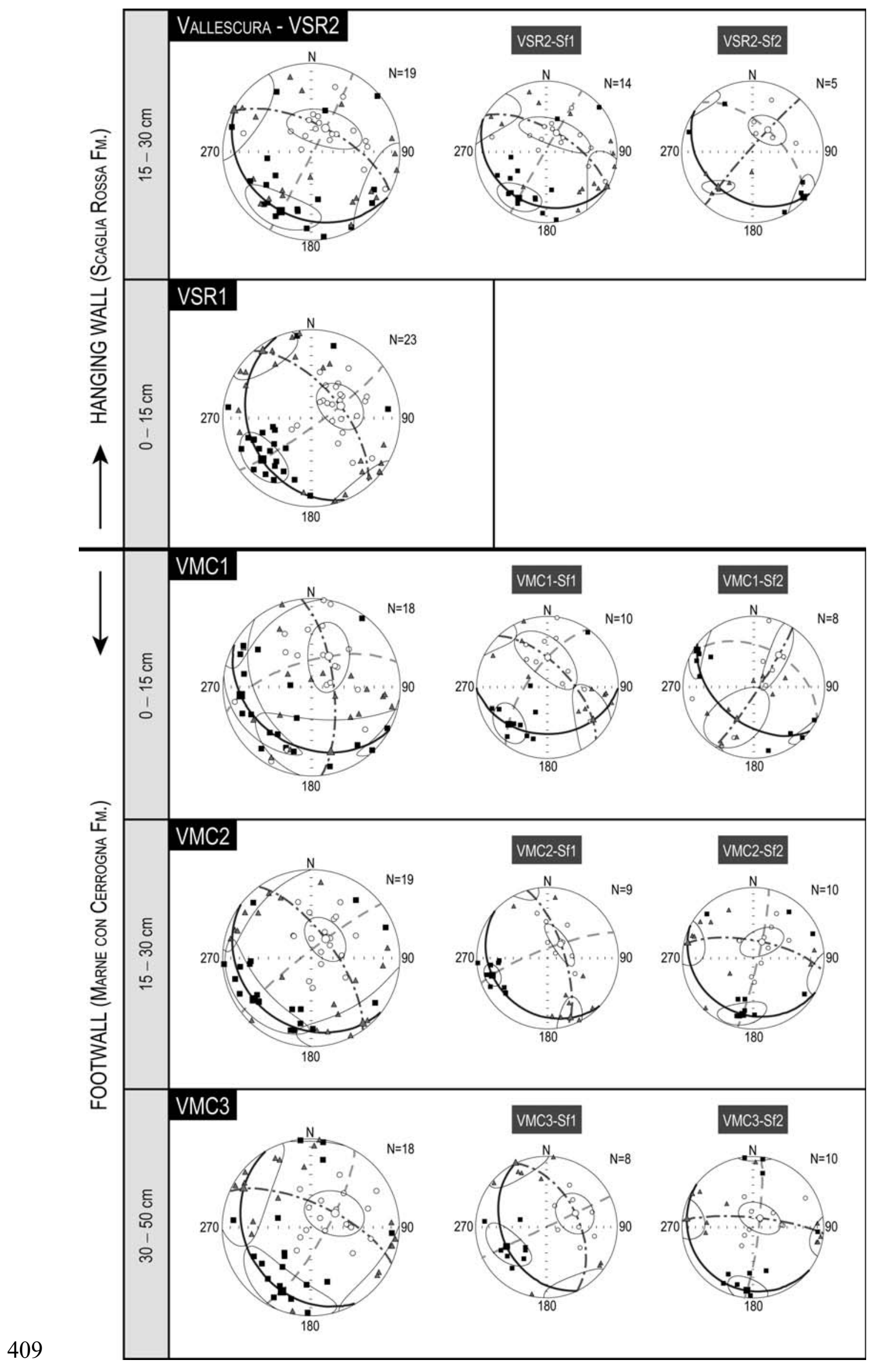


410 Figure 7 (previous page): Magnetic fabric from the oblique thrust ramp at Vallescura. Equal

411 area projections in geographic coordinates of the principal magnetic susceptibility axes at site

412 level (left) and relative subfabrics when detected (middle and right). Legend as in Figure 5.

414 A closer look reveals the dominance of Subfabric 1 on the main fabric in proximity to the main

415 thrust (site CSR1). The subfabric 2 progressively becomes dominant on the definition of the

416 magnetic foliation with the increment of the distance from the fault (Fig. 8). Particularly,

417 variations in the Subfabric 1 configuration control the rotation of $\mathrm{k}_{1}$ and $\mathrm{k}_{2}$ axes. In fact, from

418 site CSR3 to CSR1 the progressive verticalization of the magnetic foliation is associated with

419 a CCW rotation of $\mathrm{k}_{1}$ axis from $\mathrm{N} 20^{\circ}$ to NNW. On the contrary, in all sites the subfabric 2

420 shows stable NW-SE trending orientation of the magnetic lineation. In these cases, $\mathrm{k}_{1}$ acts as a

421 rotation pin producing a progressive switch between $\mathrm{k}_{3}$ and $\mathrm{k}_{2}$ axes and the verticalization of

422 the magnetic foliation when getting closer to the main thrust.

\section{5. Comparison with structural data}

425 Magnetic fabric analysis revealed straightforward correlations with structural data. It was 426 possible to infer 6 different AMS fabrics, named from A to F according to the intensity of 427 deformation; symbols * and " indicate inverse fabric and parallelism with transport direction, 428 respectively.

429 In the following, we report the comparison between AMS and structural data at site level.

430 At Sassotetto, subfabric 1 is represented by a magnetic foliation parallel to the pressure solution 431 cleavage, where $\mathrm{k}_{1}$ is close to the direction of the slip vector. This subfabric may represent an 


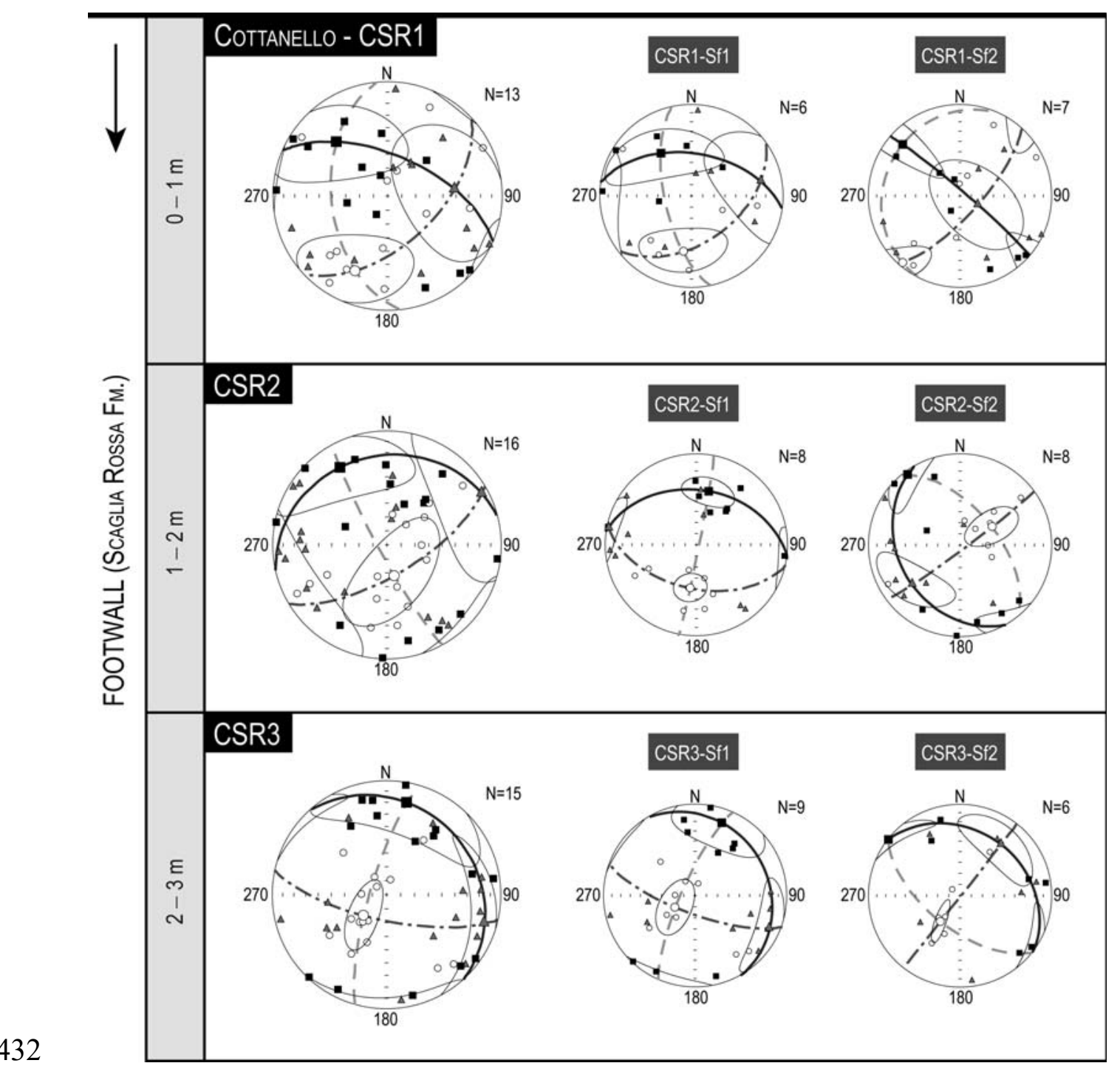

434 Figure 8: Magnetic fabric from the back-thrust at Cottanello. Equal area projections in 435 geographic coordinates of the principal magnetic susceptibility axes at site level (left) and 436 relative subfabrics (middle and right). Legend as in Figure 5.

438 advanced stage of deformation with $\mathrm{k}_{1}$ parallel to the transport direction (Stage E, Fig. 9). In 439 the same locality, subfabric 2 shows $\mathrm{k}_{1}$ and $\mathrm{k}_{3}$ consistent with $\mathrm{S} / \mathrm{C}$ intersection and $\mathrm{S}$ pole, 440 respectively. It represents the early stage of shearing with $\mathrm{k}_{1}$ at the $\mathrm{S} / \mathrm{C}$ intersection (Stage $\mathrm{C}$, 
Fig. 9).

442 At Monastero, a different magnetic fabric is documented in sites MSC1 and MSC2, sampled

443 at $15 \mathrm{~m}$ and $45 \mathrm{~m}$ from the main thrust, respectively. In site MSC1, $\mathrm{k}_{1}$ is at the $\mathrm{S} / \mathrm{C}$ intersection 444 and the magnetic foliation is parallel to the $\mathrm{S}$ plane. In particular, subfabric 1 reveals the 445 coincidence between $\mathrm{k}_{3}$ and $\mathrm{S}$ pole, but $\mathrm{k}_{1}$ axes are dispersed in the foliation plane parallel to 446 S. Subfabric 2, instead, reveals a better clustering of $\mathrm{k}_{1}$, aligned with the $\mathrm{S} / \mathrm{C}$ intersection. Here, 447 the two subfabrics may represent the same process of earlier deformation stages (Stage C) with 448 a better definition of the tectonic fabric in subfabric 2 due to higher $\chi_{\mathrm{m}}$ values.

449 In site MSC2, subfabric 1 shows an horizontal magnetic foliation consistent with the bedding 450 and moderate dispersion of $\mathrm{k}_{1}$ and $\mathrm{k}_{2}$ axis, representing the preserved sedimentary fabric of the 451 Scaglia Cinerea Fm. (Stage A, Fig. 9). In subfabric 2, $\mathrm{k}_{2}$ and $\mathrm{k}_{3}$ are dispersed on a girdle and $452 \mathrm{k}_{1}$ is at the $\mathrm{S} / \mathrm{C}$ intersection. This configuration might represent the early stage of deformation 453 (Stage B), where the sedimentary fabric is partially preserved and $\mathrm{k}_{1}$ corresponds to the 454 intersection lineation between bedding and cleavage. In fact, in incipient deformation stage the 455 magnetic foliation remains parallel to the bedding while the magnetic lineation becomes perpendicular to the bedding-parallel shortening. When the deformation increases the magnetic

457 foliation poles create a girdle parallel to the shortening (Hrouda and Chadima, 2019). 458 Furthermore, principal axes of maximum susceptibility are particularly sensitive to tectonic 459 shortening, as they develop a magnetic lineation that mimics the intersection of bedding and 460 tectonic flattening plane (Parés, 2015).

461 At Infernaccio, the subfabric 1 shows the parallelism between magnetic foliation and S plane, 462 and $\mathrm{k}_{1}$ is moving toward the slip vector direction (Stage D, Fig. 9). On the contrary, subfabric 4632 reveals $\mathrm{k}_{1}$ axes at high angle in respect to the $\mathrm{S} / \mathrm{C}$ intersection and sub-parallel to the slip 464 vector (Stage E, Fig. 9). 
465 Where the magnetic lineation is mainly defined by paramagnetic carriers, it evolves from 466 parallelism to the $\mathrm{S} / \mathrm{C}$ intersection during earlier deformational stages to parallelism to the slip 467 vector in advanced stages (Parés et al., 1999; Pueyo Anchuela et al., 2010).

468 The configuration of the subfabric 1 is consistent between Sassotetto and Infernaccio, differing only by $24^{\circ}$ in the magnetic foliation orientation. Instead, the subfabric 2 shows an increment in $\mathrm{k}_{1}$ axis inclination. On the contrary, at Monastero a change in magnetic foliation dipping angle is visible in both subfabrics. Particularly, subfabric 1 shows a $61^{\circ} \mathrm{CW}$ rotation of the magnetic lineation associated with the verticalization of the magnetic foliation from site MSC1 to site MSC2. In both sites, the subfabric 2 shows a consistent sub-horizontal N-S trending magnetic lineation. Only an increment in the magnetic foliation dipping is here visible.

Overall, the simple-shear-dominated deformation regime (Calamita et al., 2012) from the frontal ramp shows a magnetic foliation parallel to the $\mathrm{S}$ or in between $\mathrm{S}$ and $\mathrm{C}$ planes and $\mathrm{k}_{1}$ parallel to the $\mathrm{S} / \mathrm{C}$ intersection or to the slip vector, depending on the degree of deformation (from Stage C to E). Sedimentary features and early stage of cleavage development are also visible at site MSC2 (45 $\mathrm{m}$ from the thrust).

A similar behaviour is documented at Cottanello, where all 3 sites show a magnetic foliation with an intermediate orientation between $\mathrm{S}$ and $\mathrm{C}$ planes and $\mathrm{k}_{1}$ axes dispersed from the $\mathrm{S} / \mathrm{C}$ intersection toward the slip vector (inferred from the $\mathrm{S} / \mathrm{C}$ intersection). A magnetic foliation at an intermediate position between $\mathrm{S}$ and $\mathrm{C}$ planes was previously described in other fault zones, both under extensional and compressional regimes (Aranguren et al., 1996; Casas-Sainz et al., 2017). Such relationships can be explained by both deformational and mineralogical controls

486 (Casas-Sainz et al., 2018).

487 Particularly at site CSR1, the subfabric 1 shows a magnetic foliation parallel to the $\mathrm{S}$ and 488 slightly dispersion of $\mathrm{k}_{1}$ between the $\mathrm{S} / \mathrm{C}$ intersection and the slip vector (Stage D in Fig.9). At 
sites CSR2 and CSR3, it shows a magnetic foliation parallel to the $\mathrm{C}$ and $\mathrm{k}_{1}$ consistent with the

490 inferred slip vector (Stage E).

491 In all sites, subfabric 2 shows a parallelism between $\mathrm{k}_{1}$ and the $\mathrm{S} / \mathrm{C}$ intersection (Stage $\mathrm{C}$ ),

492 representing the intersection lineation, while the magnetic foliation is characterized by the same

493 strike of C plane, but variable dipping angles. In fact, at site CSR $1, \mathrm{k}_{2}$ and $\mathrm{k}_{3}$ are dispersed on

494 a girdle, while at site CSR3 the magnetic foliation shows an intermediate orientation between

$495 \mathrm{~S}$ and C planes. On the contrary, site CSR2 shows a SW dipping magnetic foliation.

496 The sub-simple shear of Cottanello (Pace et al., 2015) shows a magnetic foliation intermediate

497 between $\mathrm{S}$ and $\mathrm{C}, \mathrm{k}_{1}$ parallel to the $\mathrm{S} / \mathrm{C}$ intersection or the slip vector, depending on the degree

498 of deformation witnessed by groups of specimens.

499 At Vallescura and Boragine, the sampling was done across the thrust plane, both in the hanging500 wall and footwall block.

501 In the hanging-wall block of Vallescura, site VSR1 and subfabric 1 of VSR2 show the magnetic

502 foliation consistent with the $\mathrm{S}$ plane and $\mathrm{k}_{1}$ parallel to the transport direction (Stage E"/, Fig.9).

503 The subfabric 2 of site VSR2 reveals a $\mathrm{k}_{1}$ axis coincident with the E-E' intersection (Stage F,

504 Fig. 9).

505 In the footwall block, also VMC1 magnetic fabric shows a parallelism between magnetic 506 foliation and $\mathrm{S}$ plane. The subfabric 1 is characterized by a fan dispersion of $\mathrm{k}_{2}$ and $\mathrm{k}_{3}$ and $\mathrm{k}_{1}$ 507 parallel to the transport direction (Stage $\mathrm{E}^{/}$), while subfabric 2 reveals $\mathrm{k}_{1}$ axis parallel to the E508 E' intersection (Stage F). In both VMC2 e VMC3 the subfabric 1 is characterized by the 509 parallelisms between magnetic foliation and $\mathrm{S}$ planes, and $\mathrm{k}_{1}$ is grouped in an intermediate 510 orientation between the $\mathrm{S} / \mathrm{T}$ intersection and the transport direction (Stage $\mathrm{D}^{\mathrm{N}}$ ). On the contrary,

511 in both sites subfabric 2 shows a parallelism between magnetic foliation planes and S planes.

$512 \mathrm{k}_{1}$ axes are N-S trending and may indicate a parallelism with the inferred slip vector (Stage 
$\left.513 \mathrm{E}^{(/ /)}\right)$.

514 At Boragine most sites show low bulk magnetic susceptibility values $\left(\mathrm{k}_{\mathrm{m}}\right)$, close to the

515 instrumental limit. This might have caused problems related to mean tensors and their

516 confidence ellipses calculation. For that reason, only site BMC2, characterized by high $\chi_{\mathrm{m}}$

517 values, is considered reliable for further interpretations. However, for the sake of completeness,

518 we reported the comparison between AMS and structural data for all sites.

519 In the hanging wall, sites BSR1 and BSR2 show highly scattered axes, with $\mathrm{k}_{1}$ mostly

520 subvertical and dispersed on a $\mathrm{E}-\mathrm{W}$ girdle. In both sites $\mathrm{k}_{3}$ is partially grouped at the E-E' 521 intersection (Stage $\mathrm{F}^{*}$ ). At site $\mathrm{BMC1}, \mathrm{k}_{2}$ and $\mathrm{k}_{3}$ axes are highly dispersed along a N-S girdle,

522 while $\mathrm{k}_{1}$ axes are grouped in the transport direction (Stage $\mathrm{E}^{/ /}$).

523 At site BMC2, the subfabric 1 shows a magnetic foliation intermediate between $\mathrm{S}$ and $\mathrm{T}$ planes

524 and $\mathrm{k}_{1}$ has a double tendency to parallelize with the direction of the slip vector and the transport 525 direction (Stage $\mathrm{E}$ or $\mathrm{E}^{/ /}$in Fig. 9). The subfabric 2 is characterized by a magnetic foliation 526 parallel to $\mathrm{S}$ planes and $\mathrm{k}_{1}$ intermediate between $\mathrm{S} / \mathrm{T}$ intersection and the slip vector (Stage $\mathrm{D}^{/ /}$,

527 Fig. 9).

528 Finally, in BMC3, subfabric 1 shows a subhorizontal magnetic foliation with interdispersed $\mathrm{k}_{2}$ 529 and $\mathrm{k}_{3}$ axes, while $\mathrm{k}_{1}$ are mostly grouped with double tendency in the slip vector and the 530 transport directions. Subfabric 2 shows high dispersed $\mathrm{k}_{1}$ and $\mathrm{k}_{2}$ axes, while $\mathrm{k}_{3}$ is grouped at 531 high angle from $\mathrm{N}$ to $\mathrm{E}$. The fabric is inverse and $\mathrm{k}_{3}$ might be considered to assume an 532 orientation intermediate between the directions of the slip vector and the inferred slip vector. 


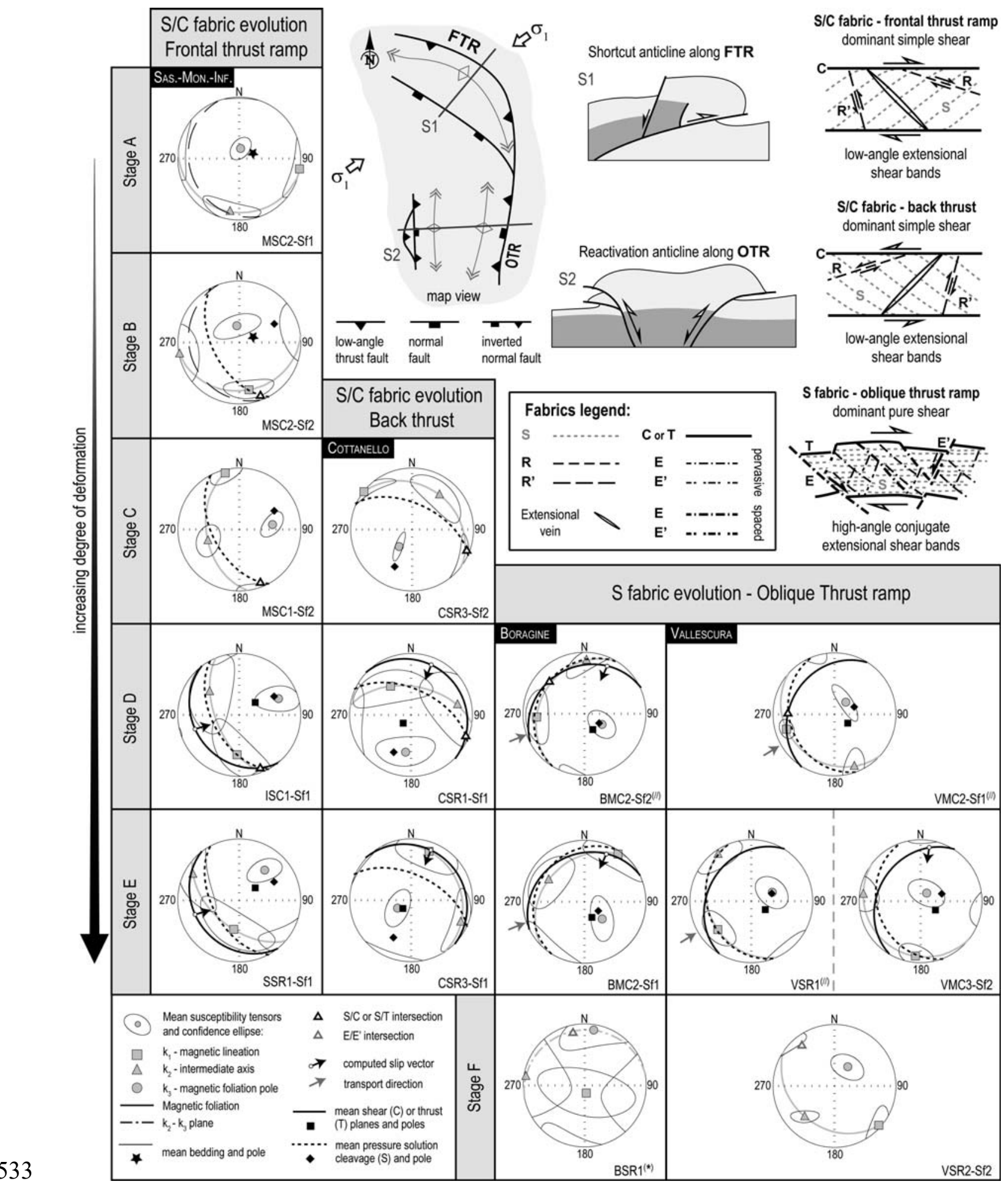

535 Figure 9: Summary of magnetic fabric stages and comparison with structural data.

536 Representative examples from the different deformation regimes are reported. Conceptual

537 diagram of the different types of shear deformation fabric (ZX section of strain ellipses) related 
539 al., 2015).

540

541 In this pure-shear-dominated deformation regime (Calamita et al., 2012) the magnetic foliation

542 is mostly parallel to $\mathrm{S}$, even if some sites from Boragine show additional complexities where

$543 \mathrm{k}_{1}$ (or $\mathrm{k}_{3}$ in case of possible inverse fabric) are: i. parallel to the slip vector (Stage E or E*); ii.

544 parallel to the transport direction (Stage $\mathrm{E}^{/ /}$); iii. in between the $\mathrm{S} / \mathrm{T}$ intersection and the slip 545 vector (Stage $\mathrm{D}^{/ /}$or $\mathrm{D}^{*}$ ); iv. parallel to the E-E' intersection close to the main thrust (Stage $\mathrm{F}$ 546 or $\left.\mathrm{F}^{*}\right)$.

\section{6. Conclusion}

549 We investigated the magnetic anisotropy in shear zones from 3 sectors of the Northern

550 Apennines fold-and-thrust belt, characterized by different combinations of simple and pure 551 shear (Calamita et al., 2012; Pace et al., 2015): the OAS frontal thrust ramp, the OAS oblique 552 ramp and an inner sector characterized by a back-thrust in a transpressive context.

553 The documented magnetic fabric shows similar evolution in all the deformation regimes, 554 depending upon the increasing of deformation (lower vorticity number) and proximity to the 555 main thrust (Fig. 9). Six different fabrics were identified:

556 A. sedimentary fabric characterized by magnetic foliation-bedding parallelism (Hrouda and

557 Chadima, 2019 and references therein);

558 B. an early stage of deformation with $\mathrm{k}_{1}$ at the intersection between bedding and $\mathrm{S}$ plane (so 559 called intersection lineation; Hrouda and Chadima, 2019); 
560 C. magnetic foliation parallel to $\mathrm{S}$ and $\mathrm{k}_{1}$ parallel to the $\mathrm{S} / \mathrm{C}$ intersection, progressively evolving

561 with the deformation increments (Parés et al., 1999; Pueyo Anchuela et al., 2010) in stage D;

562 D. magnetic foliation parallel to $\mathrm{S}$ and $\mathrm{k}_{1}$ (or $\mathrm{k}_{3}$ in case of possible inverse fabrics documented

563 in Boragine) intermediate between $\mathrm{S} / \mathrm{C}$ intersection and the slip vector. In case of pure-shear-

564 dominated regime, $\mathrm{k}_{1}$ is intermediate between $\mathrm{S} / \mathrm{T}$ intersection and the transport direction;

565 E. the magnetic foliation shows a double tendency to parallelize either the $\mathrm{S}$ or the $\mathrm{C}$ planes, 566 and $\mathrm{k}_{1}$ is parallel to the slip vector or the transport direction (in case of pure shear component);

567 F. documented in pure-shear-dominated deformation regime only, shows the parallelism 568 between $\mathrm{k}_{1}$ (or $\mathrm{k}_{3}$ in case of possible inverse fabrics) axis and extensional planes intersection.

569 These results show that the magnetic fabric is more sensitive to the simple shear deformation, 570 as the magnetic lineation tends to parallelize mostly with the computed slip vector. In pure571 shear dominated regimes, the magnetic lineation becomes parallel to the transport direction 572 when the deformation is really intense (sites at less than $15-30 \mathrm{~cm}$ from the thrust plane).

573 These results suggest that it is fundamental to use a combination of density diagrams and cluster analysis on AMS data in order to discriminate subfabrics linked to different events. In this way,

575 AMS potential as a tool to unravel different sedimentary or tectonic features is enhanced.

\section{Acknowledgments}

578 CRT, ET, EZ and SS were funded by MIUR ex-60\% attributed to SS and EZ. DS Erasmus 579 traineeship at CIMaN - ALP was funded by University of Silesia in Katowice. 
582 Supplementary Table 1: Anisotropy of magnetic susceptibility data at specimen level of all

583 the studied sites, subdivided by locality. Columns: Site; Specimen name; $\mathrm{k}_{\mathrm{m}}=$ mean bulk

584 magnetic susceptibility $(\mu \mathrm{SI})$; weight $(\mathrm{g}) ; \chi_{\mathrm{m}}=$ mean mass magnetic susceptibility $\left(10^{-9} \mathrm{~m}^{3} \mathrm{~kg}^{-}\right.$

$\left.585^{1}\right) ; \mathrm{L}=$ magnetic lineation; $\mathrm{F}=$ magnetic foliation; $\mathrm{P}^{\prime}=$ corrected anisotropy degree; $\mathrm{T}=$ shape

586 parameter; ; $\mathrm{D}=\operatorname{declination}\left({ }^{\circ}\right), \mathrm{I}=$ inclination $\left(^{\circ}\right)$ of the principal magnetic susceptibility axes

$587 \mathrm{k}_{1}, \mathrm{k}_{2}$ and $\mathrm{k}_{3}$, respectively.

588 Supplementary Table 2: Anisotropy of magnetic susceptibility data at site level for all the

589 studied localities. Columns: Locality; Site; Stage = degree of deformation from sedimentary

590 fabric $(\mathrm{A})$ to latest tectonic event $(\mathrm{F}),{ }^{(*)}$ inverse fabric and $(/)$ tectonic fabric parallel to the

591 transport direction; $\mathrm{n} / \mathrm{N}=$ number of specimens accepted/number of specimens measured; $\mathrm{k}_{\mathrm{m}}$

$592=$ mean bulk magnetic susceptibility $(\mu \mathrm{SI})$ and its standard deviation; $\chi_{\mathrm{m}}=$ mean mass magnetic

593 susceptibility $\left(10^{-9} \mathrm{~m}^{3} \mathrm{~kg}^{-1}\right)$ and its standard deviation; $\mathrm{L}=$ magnetic lineation; $\mathrm{F}=$ magnetic

594 foliation; $\mathrm{P}^{\prime}=$ corrected anisotropy degree; $\mathrm{T}=$ shape parameter; $\mathrm{D}=\operatorname{declination}\left({ }^{\circ}\right), \mathrm{I}=$

595 inclination $\left(^{\circ}\right)$ and $95 \%$ confidence angle $\left(^{\circ}\right)$ of the principal magnetic susceptibility axes $\mathrm{k}_{1}, \mathrm{k}_{2}$

596 and $\mathrm{k}_{3}$, respectively. 
599 Alberti, M., Decandia, F.A., Tavarnelli, E., 1996. Modes of propagation of the compressional 600 deformation in the Umbria-Marche Apennines. Memorie della Società Geologica Italiana $601 \quad 51,71-82$.

602 Alfonsi, L., 1995. Wrench tectonic in Central Italy, a segment of the Sabina Fault. Bollettino 603 della Società Geologica Italiana 114, 411-421.

604 Almqvist, B.S.G., Koyi, H., 2018. Bulk strain in orogenic wedges based on insights from 605

Arthur, M.A., Fischer, A.G., 1977. Upper Cretaceous-Paleocene magnetic stratigraphy at

611 Gubbio, Italy I. Lithostratigraphy and sedimentology. GSA Bulletin 88, 367-371. https://doi.org/10.1130/0016-7606(1977)88<367:UCMSAG>2.0.CO;2

613 Aubourg, C., Smith, B., Eshraghi, A., Lacombe, O., Authemayou, C., Amrouch, K., Bellier, 614 O., Mouthereau, F., 2010. New magnetic fabric data and their comparison with 615 palaeostress markers in the Western Fars Arc (Zagros, Iran): tectonic implications. 616 Geological Society, London, Special Publications 330, 97-120. 617 https://doi.org/10.1144/SP330.6

618 Berthé, D., Choukroune, P., Jegouzo, P., 1979. Orthogneiss, mylonite and non coaxial 619 deformation of granites: the example of the South Armorican Shear Zone. Journal of 620 Structural Geology 1, 31-42. https://doi.org/10.1016/0191-8141(79)90019-1 
621 Boccaletti, M., Calamita, F., Viandante, M.G., 2005. La Neo-Catena litosferica appenninica 622 nata a partire dal Pliocene inferiore come espressione della convergenza Africa-Europa. 623 Bollettino della Società Geologica Italiana 124, 87-105.

624 Borradaile, G.J., Alford, C., 1988. Experimental shear zones and magnetic fabrics. Journal of Structural Geology 10, 895-904. https://doi.org/10.1016/0191-8141(88)90102-2

626 Borradaile, G.J., Hamilton, T., 2004. Magnetic fabrics may proxy as neotectonic stress trajectories, Polis rift, Cyprus. Tectonics 23. https://doi.org/10.1029/2002TC001434

Borradaile, G.J., Henry, B., 1997. Tectonic applications of magnetic susceptibility and its anisotropy. Earth-Science Reviews 42, 49-93. https://doi.org/10.1016/S0012-

Borradaile, G.J., Jackson, M., 2004. Anisotropy of magnetic susceptibility (AMS): magnetic petrofabrics of deformed rocks. Geological Society, London, Special Publications 238, 299-360. https://doi.org/10.1144/GSL.SP.2004.238.01.18

Borradaile, G.J., Jackson, M., 2010. Structural geology, petrofabrics and magnetic fabrics

Butler, R.W.H., Tavarnelli, E., Grasso, M., 2006. Structural inheritance in mountain belts: An (AMS, AARM, AIRM). Journal of Structural Geology 32, 1519-1551. https://doi.org/10.1016/j.jsg.2009.09.006

641 Calamita, F., 1991. Extensional mesostructures in thrust shear zones examples from the 642 Umbro-Marchean Apennines. Bollettino della Società Geologica Italiana 110, 649-660.

643 Calamita, F., Coltorti, M., Piccinini, D., Pierantoni, P.P., Pizzi, A., Ripepe, M., Scisciani, V., 644 Turco, E., 2000. Quaternary faults and seismicity in the Umbro-Marchean Apennines 

245-264. https://doi.org/10.1016/S0264-3707(99)00054-X

647 Calamita, F., Decandia, F.A., Deiana, G., Fiori, A.P., 1991. Deformation of SC tectonites in 648 the Scaglia Cinera Formation in the Spoleto area (Southeast Umbria). Bollettino della 649 Società Geologica Italiana 110, 661-665.

650 Calamita, F., Deiana, G., Invernizzi, C., Mastrovincenzo, S., 1987. Analisi strutturale della 651 «Linea Amona-Anzio» Auct. tra Cittareale e Micigliano (Rieti). Bollettino della Società 652 Geologica Italiana 106, 365-375.

653 Calamita, F., Satolli, S., Scisciani, V., Esestime, P., Pace, P., 2011. Contrasting styles of fault 654 reactivation in curved orogenic belts: Examples from the Central Apennines (Italy). GSA Bulletin 123, 1097-1111. https://doi.org/10.1130/B30276.1

Calamita, F., Satolli, S., Turtù, A., 2012. Analysis of thrust shear zones in curve-shaped belts: Deformation mode and timing of the Olevano-Antrodoco-Sibillini thrust

Caricchi, C., Cifelli, F., Kissel, C., Sagnotti, L., Mattei, M., 2016. Distinct magnetic fabric in 661 weakly deformed sediments from extensional basins and fold-and-thrust structures in the Northern Apennine orogenic belt (Italy). Tectonics 35, 238-256. https://doi.org/10.1002/2015TC003940

Casas-Sainz, A.M., Gil-Imaz, A., Simón, J.L., Izquierdo-Llavall, E., Aldega, L., RománBerdiel, T., Osácar, M.C., Pueyo-Anchuela, Ó., Ansón, M., García-Lasanta, C., Corrado, S., Invernizzi, C., Caricchi, C., 2018. Strain indicators and magnetic fabric in intraplate fault zones: Case study of Daroca thrust, Iberian Chain, Spain. Tectonophysics 730, 2947. https://doi.org/10.1016/j.tecto.2018.02.013 
Casas-Sainz, A.M., Román-Berdiel, T., Oliva-Urcia, B., García-Lasanta, C., Villalaín, J.J., Aldega, L., Corrado, S., Caricchi, C., Invernizzi, C., Osácar, M.C., 2017. Multidisciplinary approach to constrain kinematics of fault zones at shallow depths: a case study from the Cameros-Demanda thrust (North Spain). Int J Earth Sci (Geol Rundsch) 106, 1023-1055. https://doi.org/10.1007/s00531-016-1349-5

Castellarin, A., Colacicchi, R., Praturlon, A., Cantelli, C., 1982. The Jurassic-Lower Pliocene history of the Ancona-Anzio Line (Central Italy). Mem. Soc. Geol. Ital 24, 325-336.

Centamore, E., Micarelli, A., 1991. L'ambiente fisico delle Marche. Geologia, Geomorfologia, Idrogeologia (scala 1: 100. 000).

Chadima, M., Jelínek, V., 2008. Anisoft 4.2.-Anisotropy data browser. Contributions to Geophysics and Geodesy 38, 38-41.

Ciarapica, G., Passeri, L., 2002. The palaeogeographic duplicity of the Apennines. Boll. Soc. Geol. It. 1, 67-75.

Di Domenica, A., Turtù, A., Satolli, S., Calamita, F., 2012. Relationships between thrusts and normal faults in curved belts: New insight in the inversion tectonics of the CentralNorthern Apennines (Italy). Journal of Structural Geology 42, 104-117. https://doi.org/10.1016/j.jsg.2012.06.008

Ferré, E.C., Gébelin, A., Till, J.L., Sassier, C., Burmeister, K.C., 2014. Deformation and magnetic fabrics in ductile shear zones: A review. Tectonophysics 629, 179-188. https://doi.org/10.1016/j.tecto.2014.04.008

Fossen, H., 2010. Structural Geology. Cambridge University Press. https://doi.org/10.1017/CBO9780511777806

Fossen, H., Cavalcante, G.C.G., 2017. Shear zones - A review. Earth-Science Reviews 171, 434-455. https://doi.org/10.1016/j.earscirev.2017.05.002 
693 Ghisetti, F., 1987. Mechanisms of thrust faulting in the Gran Sasso chain, Central Apennines,

694 Italy. Journal of Structural Geology 9, 955-967. https://doi.org/10.1016/0191$695 \quad \underline{8141(87) 90004-6}$

696 Graham, J.W., 1966. Significance of Magnetic Anisotropy in Appalachian Sedimentary Rocks,

697 in: Steinhart, J.S., Smith, T.J. (Eds.), Geophysical Monograph Series. American

698 Geophysical Union, Washington, D. C., pp. 627-648.

699 https://doi.org/10.1029/GM010p0627

700 Harris, L.B., Cobbold, P.R., 1985. Development of conjugate shear bands during bulk simple

701 shearing. Journal of Structural Geology 7, 37-44. https://doi.org/10.1016/0191-

$702 \quad \underline{8141(85) 90113-0}$

703 Holdsworth, R.E., Strachan, R.A., Alsop, G.I., Grant, C.J., Wilson, R.W., 2006. Thrust 704 sequences and the significance of low-angle, out-of-sequence faults in the northernmost 705 Moine Nappe and Moine Thrust Zone, NW Scotland. Journal of the Geological Society 706

Housen, B.A., Van Der Pluijm, B.A., Essene, E.J., 1995. Plastic behavior of magnetite and 708 high strains obtained from magnetic fabrics in the Parry Sound shear zone, Ontario Grenville Province. Journal of Structural Geology 17, 265-278. https://doi.org/10.1016/0191-8141(94)E0045-Z

Hrouda, F., 2002. Low-field variation of magnetic susceptibility and its effect on the anisotropy

714 Hrouda, F., Chadima, M., 2019. Examples of tectonic overprints of magnetic fabrics in rocks 715 of the Bohemian Massif and Western Carpathians. Int J Earth Sci (Geol Rundsch). https://doi.org/10.1007/s00531-019-01786-8 
717 Hrouda, F., Ježek, J., 1999. Magnetic anisotropy indications of deformations associated with

718 diagenesis. Geological Society, London, Special Publications 151, 127-137.

719 https://doi.org/10.1144/GSL.SP.1999.151.01.13

720 ISPRA, 2007, Carta Geologica d'Italia 1:50.000 - Catalogo delle Formazioni, Periodici tecnici

$721 \quad$ Volume 7

722 Jégouzo, P., 1980. The South Armorican Shear Zone. Journal of Structural Geology, Shear 723 zones in rocks 2, 39-47. https://doi.org/10.1016/0191-8141(80)90032-2

724

Jelínek, V., 1977. The statistical theory of measuring anisotropy of magnetic susceptibility of rocks and its application. Geofyzika Brno, Czech Republic.

Jelínek, V., 1981. Characterization of the magnetic fabric of rocks. Tectonophysics 79, T63T67. https://doi.org/10.1016/0040-1951(81)90110-4

Koopman, A., 1983. Detachment tectonics in the Central Apennines, Italy. Geologica Ultraiectina $30,1-55$.

730

Lavecchia, G., 1985. Il sovrascorrimento dei Monti Sibillini: analisi cinematica e strutturale. Bollettino della Società Geologica Italiana 104, 161-194.

Lister, G.S., Snoke, A.W., 1984. S-C Mylonites. Journal of Structural Geology 6, 617-638. https://doi.org/10.1016/0191-8141(84)90001-4

Mattei, M., Funiciello, R., Kissel, C., 1995. Paleomagnetic and structural evidence for Neogene block rotations in the Central Apennines, Italy. J. Geophys. Res. 100, 17863-17883.

Pace, P., Calamita, F., 2014. Push-up inversion structures v. fault-bend reactivation anticlines along oblique thrust ramps: examples from the Apennines fold-and-thrust belt (Italy). Journal of the Geological Society 171, 227-238. https://doi.org/10.1144/jgs2013-053

740 Pace, P., Calamita, F., Tavarnelli, E., 2015. Brittle-ductile shear zones along inversion-related frontal and oblique thrust ramps: Insights from the Central-Northern Apennines curved 
thrust system (Italy), in: Mukherjee, S., Mulchrone, K.F. (Eds.), Ductile Shear Zones. John Wiley \& Sons, Ltd, Chichester, UK, pp. 111-127. https://doi.org/10.1002/9781118844953.ch8

745

Parés, J.M., 2015. Sixty years of anisotropy of magnetic susceptibility in deformed sedimentary rocks. Front. Earth Sci. 3. https://doi.org/10.3389/feart.2015.00004

Parés, J.M., van der Pluijm, B.A., 2002. Evaluating magnetic lineations (AMS) in deformed rocks. Tectonophysics 350, 283-298. https://doi.org/10.1016/S0040-1951(02)00119-1

Parés, J.M., van der Pluijm, B.A., Dinarès-Turell, J., 1999. Evolution of magnetic fabrics during incipient deformation of mudrocks (Pyrenees, northern Spain). Tectonophysics 307, 1-14. https://doi.org/10.1016/S0040-1951(99)00115-8

Passchier, C.W., 2001. Flanking structures. Journal of Structural Geology 23, 951-962. https://doi.org/10.1016/S0191-8141(00)00166-8

Pierantoni, P.P., 1996. Faglie trascorrenti sin-thrusting come ripartizione della deformazione: L’esempio della Faglia Sabina (Appennino Centrale). Studi Geologici Camerti 14, 279289.

Platt, J.P., 1984. Secondary cleavages in ductile shear zones. Journal of Structural Geology 6, 439-442. https://doi.org/10.1016/0191-8141(84)90045-2

Platt, J.P., Vissers, R.L.M., 1980. Extensional structures in anisotropic rocks. Journal of Structural Geology 2, 397-410. https://doi.org/10.1016/0191-8141(80)90002-4

Ponce de Leon, M.I., Choukroune, P., 1980. Shear zones in the iberian arc. Journal of Structural Geology, Shear zones in rocks 2, 63-68. https://doi.org/10.1016/0191-8141(80)90035-8

Pueyo Anchuela, Ó., Pocoví Juan, A., Gil Imaz, A., 2010. Tectonic imprint in magnetic fabrics in foreland basins: A case study from the Ebro Basin, N Spain. Tectonophysics 492, 150163. https://doi.org/10.1016/j.tecto.2010.06.016 
Ramsay, J.G., 1980. Shear zone geometry: A review. Journal of Structural Geology 2, 83-99. https://doi.org/10.1016/0191-8141(80)90038-3

Ramsay, J.G., Graham, R.H., 1970. Strain variation in shear belts. Can. J. Earth Sci. 7, 786-

\section{3. https://doi.org/10.1139/e70-078}

770

771

772

773

774

775

776

777

778

779

780

781

782

783

784

785

786

787

788

789

790

Ramsay, J.G., Huber, M.I., 1987. The Techniques of Modern Structural Geology, in: Folds and Fractures, Vol. II. Academic Press, London.

Riedel, W., 1929. Zur Mechanik geologischer Brucherscheinungen. Ein Beitrag zum Problem der Fiederspatten. Zentbl. Miner. Geol. Palaont. Abt. 354-368.

Robustelli Test, C., Festa, A., Zanella, E., Codegone, G., Scaramuzzo, E., 2019. Distinguishing the Mélange-Forming Processes in Subduction-Accretion Complexes: Constraints from the Anisotropy of Magnetic Susceptibility (AMS). Geosciences 9, 381. https://doi.org/10.3390/geosciences9090381

Röller, K., Trepmann, C.A., 2008. Stereo32 v1.0.1 Software and helpfile. Ruhr-Universität Bochum, Institut für Geologie, Mineralogie \& Geophysik.

Scisciani, V., 2009. Styles of positive inversion tectonics in the Central Apennines and in the Adriatic foreland: Implications for the evolution of the Apennine chain (Italy). Journal of Structural Geology 31, 1276-1294. https://doi.org/10.1016/j.jsg.2009.02.004

Sidman, D., Ferré, E.C., Teyssier, C., Jackson, M., 2005. Magnetic fabric and microstructure of a mylonite: example from the Bitterroot shear zone, western Montana. Geological Society, London, $\quad$ Special Publications $\quad 245, \quad 143-163$. https://doi.org/10.1144/GSL.SP.2005.245.01.07

Tarling, D., Hrouda, F., 1993. Magnetic Anisotropy of Rocks. Chapman \& Hall, London.

Tavarnelli, E., 1997. Structural evolution of a foreland fold-and-thrust belt: the Umbria-Marche Apennines, Italy. Journal of Structural Geology, Fault-Related Folding 19, 523-534. https://doi.org/10.1016/S0191-8141(96)00093-4 
791 Tavarnelli, E., 1999. Normal faults in thrust sheets: pre-orogenic extension, post-orogenic extension, or both? Journal of Structural Geology 21, 1011-1018.

$793 \quad$ https://doi.org/10.1016/S0191-8141(99)00034-6

794 Tavarnelli, E., Butler, R.W.H., Decandia, F.A., Calamita, F., Grasso, M., Alvarez, W., Renda, 795 P., 2004. Implications of fault reactivation and structural inheritance in the Cenozoic 796 tectonic evolution of Italy, in: Crescenti, U., D’offizi, S., Merlino, S., Sacchi, S. (Eds.) The 797 Geology of Italy, Società Geologica Italiana, Special Volume, 209-222.

798 Turtù, A., Satolli, S., Maniscalco, R., Calamita, F., Speranza, F., 2013. Understanding 799 progressive-arc- and strike-slip-related rotations in curve-shaped orogenic belts: The case 800 of the Olevano-Antrodoco-Sibillini thrust (Northern Apennines, Italy). J. Geophys. Res. $801 \quad$ Solid Earth 118, 459-473. https://doi.org/10.1002/jgrb.50096

802 Weil, A.B., Yonkee, A., 2009. Anisotropy of magnetic susceptibility in weakly deformed red 803 beds from the Wyoming salient, Sevier thrust belt: Relations to layer-parallel shortening 804 and orogenic curvature. Lithosphere 1, 235-256. https://doi.org/10.1130/L42.1

805 Xypolias, P., 2010. Vorticity analysis in shear zones: A review of methods and applications. 806 Journal of Structural Geology 32, 2072-2092. https://doi.org/10.1016/j.jsg.2010.08.009 
Table 1: Summary of the anisotropy of magnetic susceptibility data at site level.

\begin{tabular}{|c|c|c|c|c|c|c|c|c|c|c|c|c|c|c|}
\hline \multirow{3}{*}{$\begin{array}{c}\text { Locality } \\
\text { Sassotetto }\end{array}$} & \multirow{3}{*}{$\begin{array}{l}\text { Site } \\
\text { SSR1 }\end{array}$} & \multirow{3}{*}{ Stage } & \multirow{3}{*}{$\begin{array}{c}\mathbf{n} / \mathbf{N} \\
16 / 20\end{array}$} & \multirow{3}{*}{$\begin{array}{c}\chi_{\mathrm{m}}( \pm \sigma) \\
\left(\mathbf{x} 10^{-9} \mathbf{m}^{3} \mathbf{k g}^{-1}\right)\end{array}$} & \multirow{3}{*}{$\begin{array}{c}\mathbf{P}^{\prime} \\
1.040\end{array}$} & \multirow{3}{*}{$\begin{array}{c}\mathbf{T} \\
0.785\end{array}$} & \multicolumn{4}{|c|}{$k_{1}$} & \multicolumn{4}{|c|}{$\mathbf{k}_{3}$} \\
\hline & & & & & & & \multirow{2}{*}{$\frac{D}{295}$} & \multirow{2}{*}{$\frac{\text { I }}{32}$} & \multicolumn{2}{|c|}{$\begin{array}{c}95 \% \text { conf. } \\
\text { angles }\end{array}$} & \multirow{2}{*}{$\frac{D}{47}$} & \multirow{2}{*}{$\frac{\mathbf{I}}{31}$} & \multicolumn{2}{|c|}{$\begin{array}{c}95 \% \text { conf. } \\
\text { angles }\end{array}$} \\
\hline & & & & & & & & & 52.1 & 18.3 & & & 21.1 & 11.6 \\
\hline & SSR1-SF1 & $E$ & $10 / 16$ & $12.71 \pm 5.76$ & 1.030 & 0.671 & 191 & 50 & 56.7 & 22.9 & 40 & 36 & 26.8 & 12.9 \\
\hline & SSR1-SF2 & C & $6 / 16$ & $8.56 \pm 2.86$ & 1.061 & 0.386 & 304 & 29 & 18.6 & 8.8 & 51 & 28 & 13.3 & 8.6 \\
\hline \multirow[t]{6}{*}{ Monastero } & MSC1 & & $19 / 20$ & $39.65 \pm 21.54$ & 1.021 & 0.613 & 342 & 5 & 35.1 & 13.5 & 76 & 39 & 18.6 & 12.1 \\
\hline & MSC1-SF1 & $\mathrm{C}$ & $8 / 19$ & $17.20 \pm 4.45$ & 1.021 & 0.903 & 161 & 2.3 & 77.5 & 12.0 & 70 & 32 & 14.4 & 8.9 \\
\hline & MSC1-SF2 & C & $11 / 19$ & $55.98 \pm 11.19$ & 1.023 & 0.465 & 346 & 6 & 19.2 & 13.2 & 82 & 45 & 20.2 & 10.7 \\
\hline & MSC2 & & $19 / 19$ & $24.69 \pm 2.66$ & 1.017 & 0.648 & 133 & 13 & 59.4 & 13.0 & 1 & 71 & 22.2 & 13.8 \\
\hline & MSC2-SF1 & $A$ & $10 / 19$ & $24.12 \pm 1.91$ & 1.019 & 0.158 & 100 & 1 & 31.8 & 12.9 & 8 & 77 & 17.0 & 11.4 \\
\hline & MSC2-SF2 & B & $9 / 19$ & $25.32 \pm 3.39$ & 1.020 & 0.052 & 169 & 22 & 28.5 & 14.2 & 351 & 68 & 32.5 & 14.2 \\
\hline \multirow[t]{3}{*}{ Infernaccio } & ISC1 & & $19 / 21$ & $22.07 \pm 7.02$ & 1.032 & 0.856 & 212 & 50 & 75.1 & 24.4 & 76 & 32 & 30.1 & 24.6 \\
\hline & ISC1-SF1 & $\mathrm{D}$ & $14 / 19$ & $18.63 \pm 2.86$ & 1.014 & 0.479 & 183 & 35 & 53.3 & 21.6 & 68 & 31 & 33.8 & 14.9 \\
\hline & ISC1-SF2 & $\mathrm{E}$ & $5 / 19$ & $31.71 \pm 6.10$ & 1.117 & 0.657 & 297 & 59 & 17.9 & 7.7 & 79 & 25 & 18.7 & 7.6 \\
\hline \multirow[t]{9}{*}{ Monte Boragine } & BSR2 & $\mathrm{F}^{*}$ & $10 / 15$ & $-2.03 \pm 0.98$ & 1.076 & -0.351 & 319 & 59 & 68.7 & 18.1 & 180 & 25 & 31.9 & 16.0 \\
\hline & BSR1 & $\mathrm{F}^{*}$ & $10 / 19$ & $-3.33 \pm 1.81$ & 1.027 & -0.656 & 169 & 80 & 70.0 & 31.0 & 9 & 10 & 43.3 & 23.9 \\
\hline & BMC1 & $E^{\prime \prime}$ & $8 / 12$ & $2.52 \pm 1.94$ & 1.055 & 0.147 & 250 & 46 & 59.9 & 27.9 & 4 & 21 & 52.9 & 20.8 \\
\hline & $\mathrm{BMC2}$ & & $13 / 16$ & $9.83 \pm 6.33$ & 1.032 & 0.593 & 243 & 13 & 43.6 & 17.3 & 128 & 61 & 25.7 & 17.3 \\
\hline & BMC2-SF1 & $E$ or $E^{\prime \prime}$ & $6 / 13$ & $6.44 \pm 2.28$ & 1.027 & 0.175 & 35 & 6 & 37.0 & 23.4 & 134 & 57 & 31.3 & 14.7 \\
\hline & BMC2-SF2 & $D^{\prime \prime}$ & $7 / 13$ & $12.74 \pm 7.37$ & 1.040 & 0.410 & 266 & 23 & 30.8 & 18.2 & 121 & 63 & 22.4 & 14.2 \\
\hline & BMC3 & & $15 / 21$ & $1.05 \pm 2.96$ & 1.121 & -0.037 & 201 & 21 & 44.2 & 24.5 & 9 & 69 & 59.4 & 23.6 \\
\hline & BMC3-SF1 & $E$ or $E^{\prime \prime}$ & $8 / 15$ & $3.34 \pm 1.96$ & 1.035 & -0.225 & 211 & 1 & 49.7 & 20.5 & 304 & 72 & 45.3 & 28.5 \\
\hline & BMC3-SF2 & $D^{*}$ & $7 / 15$ & $-1.56 \pm 1.00$ & 1.080 & 0.071 & 197 & 29 & 34.2 & 19.9 & 29 & 61 & 54.6 & 15.2 \\
\hline \multirow[t]{13}{*}{ Valle Scura } & VSR2 & & $19 / 21$ & $7.23 \pm 1.88$ & 1.022 & 0.010 & 207 & 25 & 32.2 & 17.8 & 31 & 65 & 35.3 & 16.6 \\
\hline & VSR2-SF1 & $E^{\prime \prime}$ & $14 / 19$ & $7.12 \pm 1.80$ & 1.027 & -0.383 & 211 & 25 & 23.3 & 16.7 & 28 & 65 & 43.5 & 15.2 \\
\hline & VSR2-SF2 & $\mathrm{F}$ & $5 / 19$ & $7.52 \pm 2.29$ & 1.020 & -0.134 & 132 & 4 & 23.0 & 12.1 & 35 & 59 & 22.7 & 15.6 \\
\hline & VSR1 & $E^{\prime \prime}$ & $23 / 24$ & $9.29 \pm 2.17$ & 1.039 & 0.091 & 230 & 28 & 24.3 & 18.0 & 67 & 61 & 24.3 & 18.0 \\
\hline & VMC1 & & $18 / 21$ & $8.56 \pm 3.56$ & 1.015 & 0.529 & 263 & 21 & 68.5 & 14.8 & 29 & 57 & 33.5 & 18.7 \\
\hline & VMC1-SF1 & $E^{\prime \prime}$ & $10 / 18$ & $8.16 \pm 2.22$ & 1.020 & -0.346 & 227 & 26 & 22.5 & 18.6 & 1 & 55 & 45.1 & 21.6 \\
\hline & VMC1-SF2 & $F$ & $8 / 18$ & $9.07 \pm 4.89$ & 1.023 & -0.361 & 303 & 5 & 28.3 & 9.6 & 38 & 42 & 46.0 & 10.3 \\
\hline & VCM2 & & $19 / 21$ & $12.25 \pm 2.37$ & 1.024 & 0.406 & 234 & 21 & 49.0 & 15.8 & 37 & 68 & 22.7 & 15.8 \\
\hline & VMC2-SF1 & $\mathrm{D}^{\prime \prime}$ & $9 / 19$ & $12.25 \pm 2.37$ & 1.032 & -0.004 & 253 & 19 & 11.6 & 10.5 & 43 & 68 & 28.2 & 8.7 \\
\hline & VMC2-SF2 & $E$ & $10 / 19$ & $12.42 \pm 1.51$ & 1.020 & 0.186 & 191 & 20 & 25.6 & 14.1 & 28 & 69 & 26.8 & 14.9 \\
\hline & VCM3 & & $18 / 21$ & $11.56 \pm 3.62$ & 1.022 & 0.442 & 204 & 22 & 44.0 & 20.6 & 60 & 64 & 28.3 & 20.1 \\
\hline & VMC3-SF1 & $\mathrm{D}^{\prime \prime}$ & $8 / 18$ & $11.44 \pm 3.24$ & 1.025 & 0.120 & 244 & 38 & 30.4 & 17.3 & 64 & 53 & 23.6 & 21.8 \\
\hline & VMC3-SF2 & $E$ & $10 / 18$ & $12.18 \pm 4.37$ & 1.025 & 0.181 & 185 & 12 & 21.0 & 15.1 & 37 & 77 & 25.9 & 16.3 \\
\hline Cottanello & CSR1 & & $13 / 15$ & $2.97 \pm 1.21$ & 1.025 & -0.056 & 317 & 35 & 50.4 & 26.9 & 204 & 29 & 39.4 & 26.3 \\
\hline & CSR1-SF1 & $\mathrm{D}$ & $6 / 13$ & $2.4 \pm 1.37$ & 1.039 & 0.113 & 325 & 42 & 53.5 & 22.8 & 188 & 39 & 36.8 & 21.3 \\
\hline & CSR1-SF2 & C & $7 / 13$ & $3.47 \pm 0.86$ & 1.019 & 0.097 & 312 & 17 & 51.2 & 11.4 & 221 & 5 & 30.5 & 11.4 \\
\hline & CSR2 & & $16 / 22$ & $5.72 \pm 2.79$ & 1.026 & 0.058 & 329 & 22 & 47.5 & 25.1 & 167 & 67 & 47.6 & 23.0 \\
\hline & CSR2-SF1 & $E$ & $8 / 16$ & $5.91 \pm 2.78$ & 1.045 & 0.222 & 13 & 40 & 22.2 & 13.5 & 188 & 50 & 14.6 & 13.0 \\
\hline & CSR2-SF2 & C & $8 / 16$ & $5.52 \pm 2.97$ & 1.038 & 0.329 & 324 & 4 & 32.8 & 12.9 & 60 & 57 & 27.4 & 13.6 \\
\hline & CSR3 & & $15 / 20$ & $6.76 \pm 4.20$ & 1.042 & 0.453 & 12 & 18 & 56.0 & 26.6 & 228 & 68 & 26.8 & 10.8 \\
\hline & CSR3-SF1 & $E$ & $9 / 15$ & $5.80 \pm 4.30$ & 1.049 & -0.026 & 20 & 16 & 36.0 & 26.5 & 240 & 69 & 26.8 & 14.6 \\
\hline & CSR3-SF2 & C & $6 / 15$ & $8.19 \pm 3.97$ & 1.042 & 0.395 & 308 & 1 & 37.4 & 8.0 & 217 & 61 & 20.9 & 4.8 \\
\hline
\end{tabular}

Columns: Locality; Site; Stage = degree of deformation from sedimentary fabric (A) to latest tectonic event $\left.(\mathrm{F}),{ }^{*}\right)$ inverse fabric and $(/ /)$ tectonic fabric parallel to the transport direction; $\mathrm{n} / \mathrm{N}=$ number of specimens accepted/number of specimens measured; $m=$ mean mass magnetic susceptibility $(10-9 \mathrm{~m} 3 \mathrm{~kg}-1)$ and 
Figurequaternary continental deposits

Pliocene - Pleistocene

Tortonian-Messinian

Burdigalian-Tortonian

Carbonate platform (Triassic-Miocene)

Slopebasin sucession (Triassic-Miocene)

1.Sassotto 2. Monastero 3. Infernaccio

4. Bragine 5.Vallescura 6. Cottanello

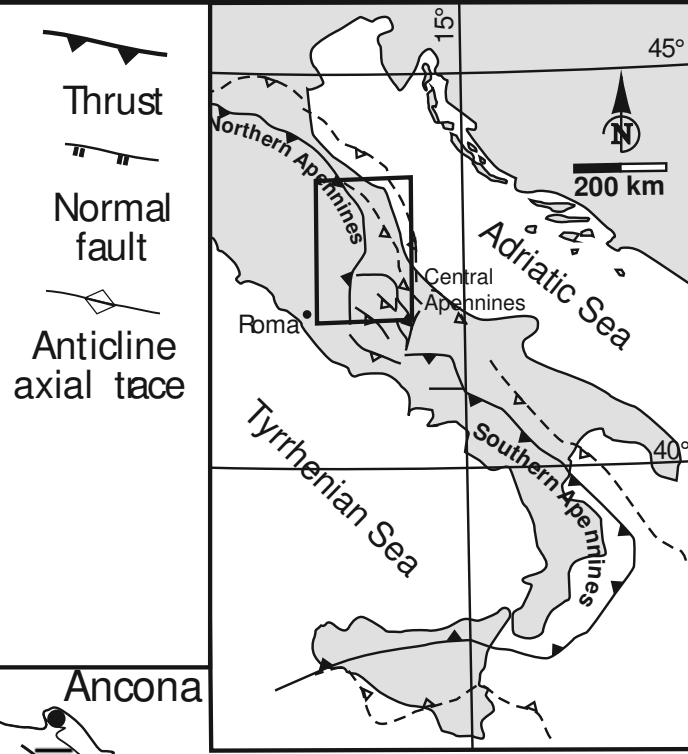

$50 \mathrm{~km}$

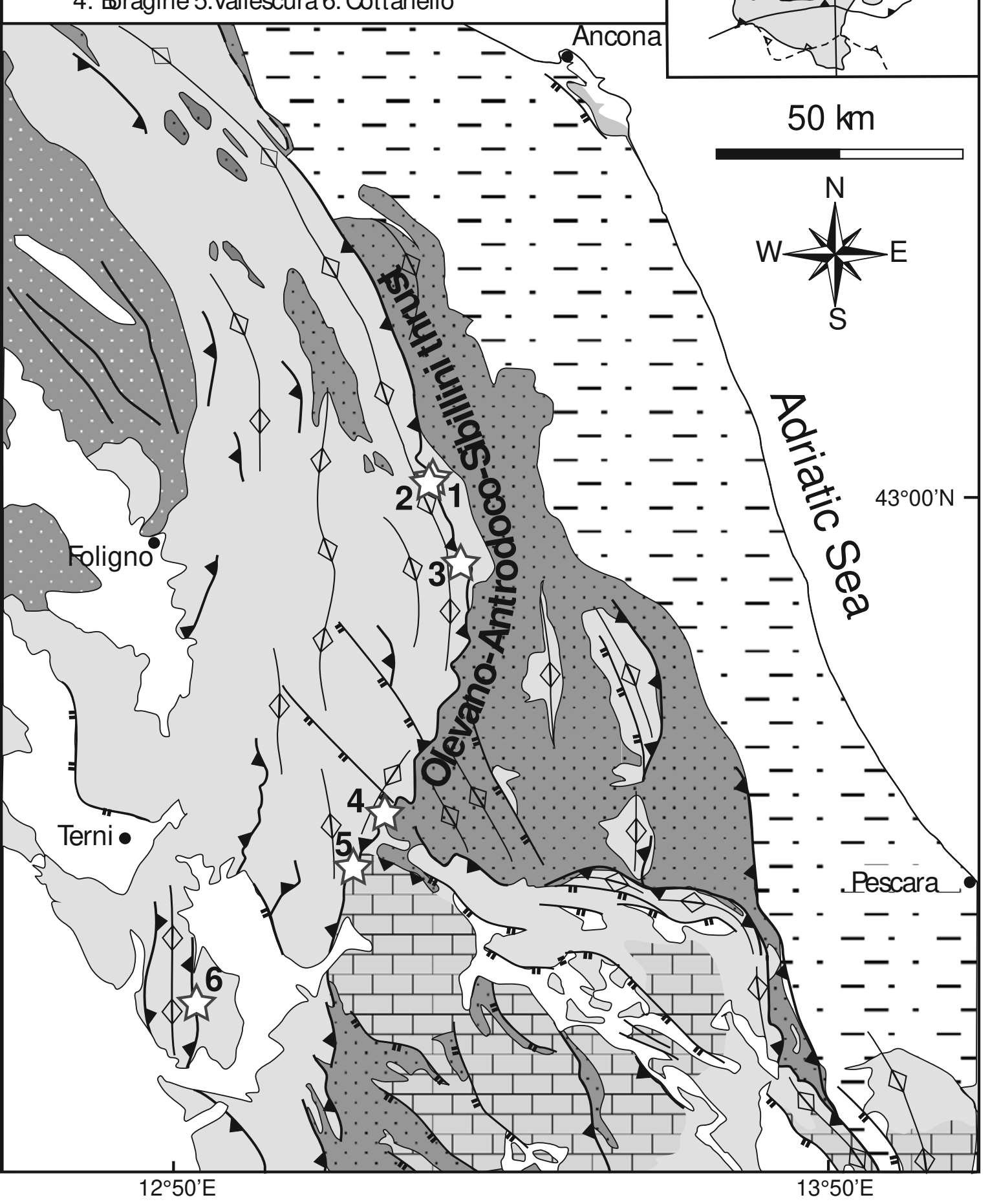

Figure 1: Schematic geological map of the Northern Apennines (Italy) with the studied localities (white stars), modified after Calamita et al. (2012). The curve-shaped Olevano-Antrodoco-Sibillini (OAS) thrust is the outer front of the Northern Apennines. 
Figure 3
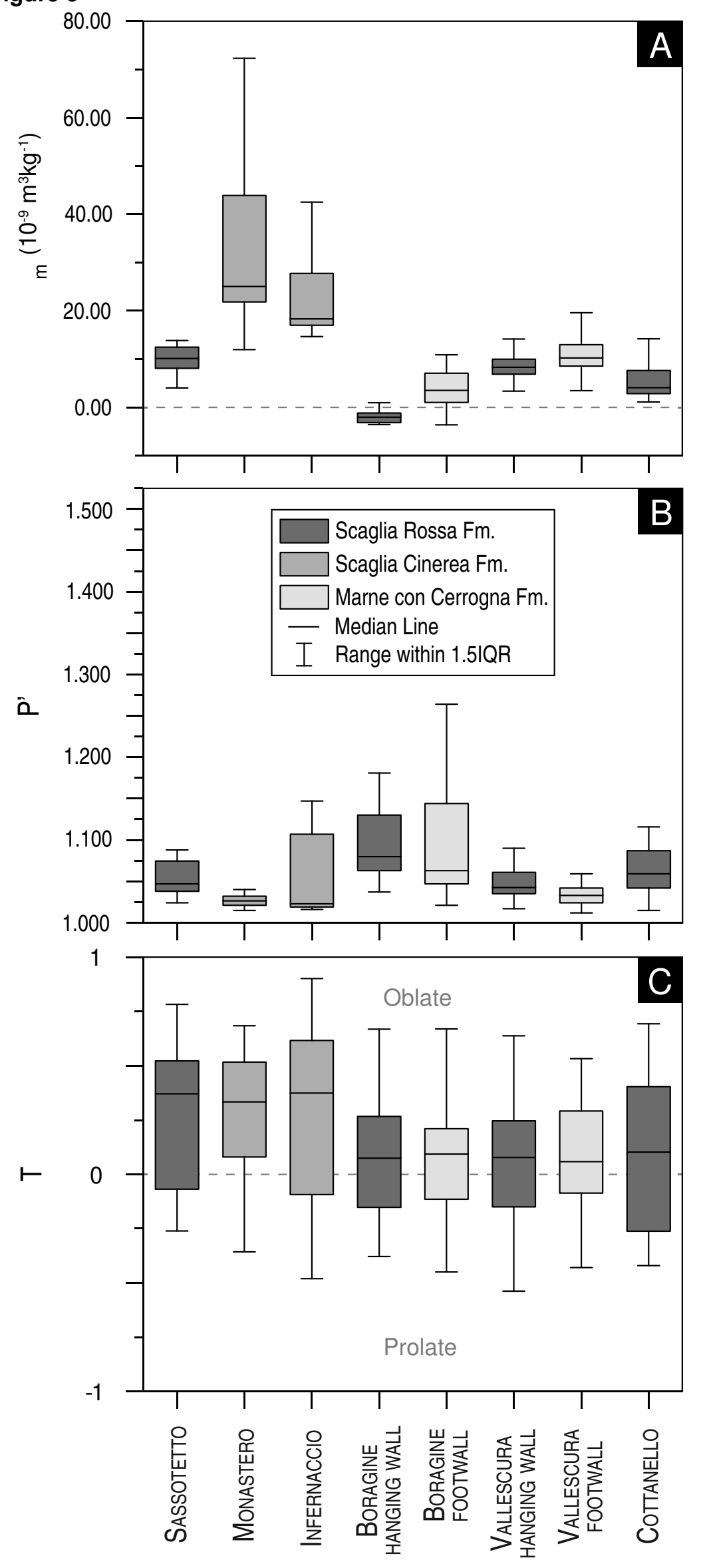

Figure 3: Box-and-whisker plots of the a) mass magnetic susceptibility $\left({ }_{\mathrm{m}}\right)$, b) corrected anisotropy degree ( $\left.P^{\prime}\right)$ and C) shape parameter (T) for the studied localities. Central boxes include values between the lower and upper quartiles. Di erent gray shades correspond to di erent lithologies. 


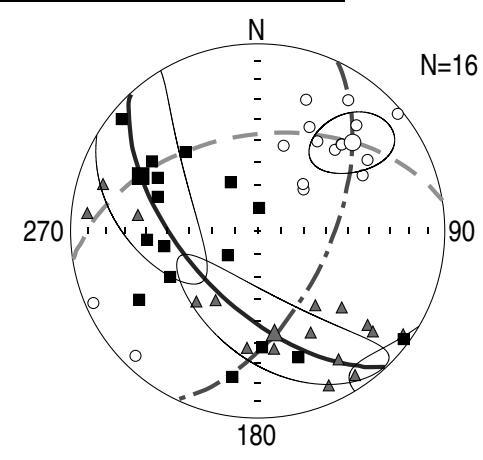

180
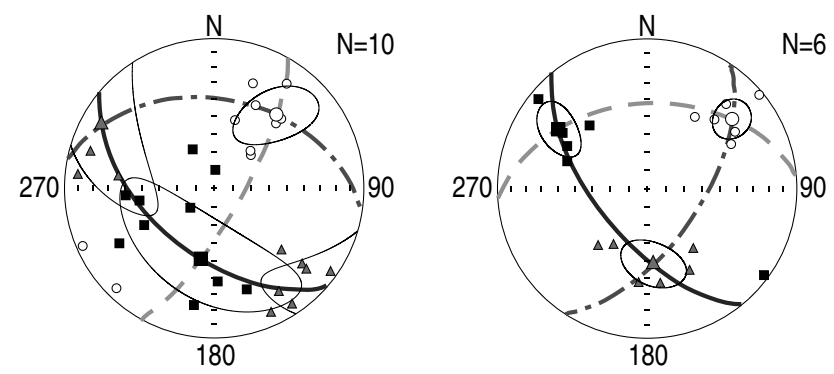

MONASTERO - MSC1
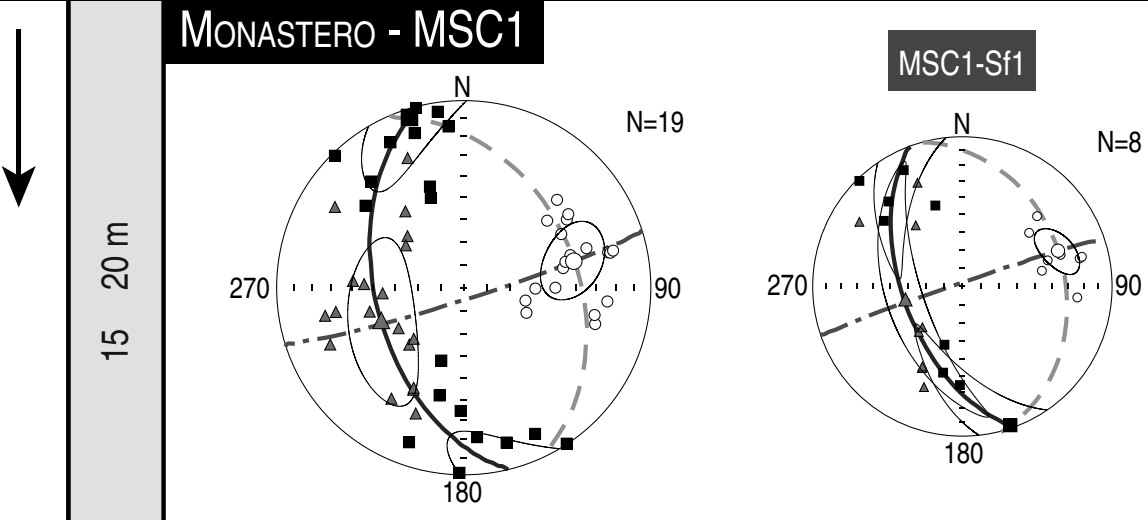

MSC1-Sf2

离

INFERNACCIO - ISC1

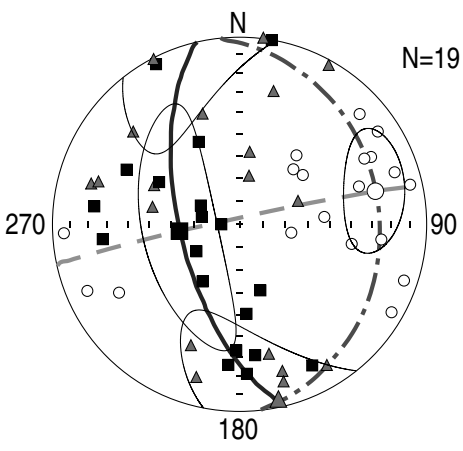

ISC1-Sf1

ISC1-Sโ2
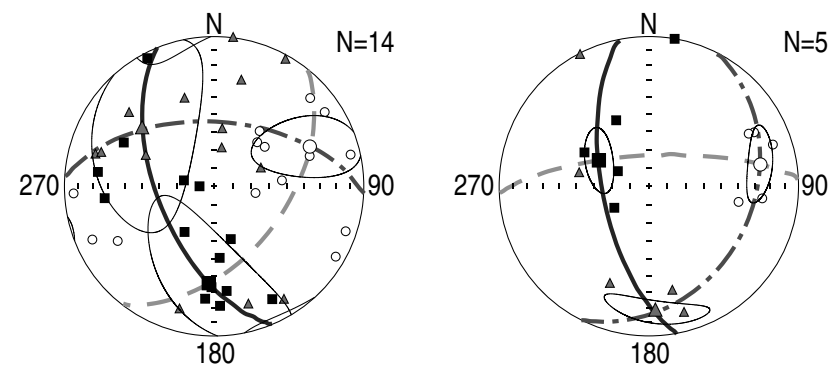

MONASTERO - MSC2

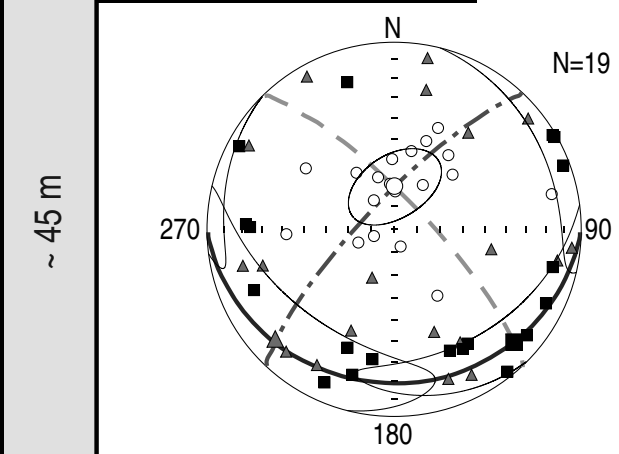

\section{MSC2-St1}

MSC2-Sf2
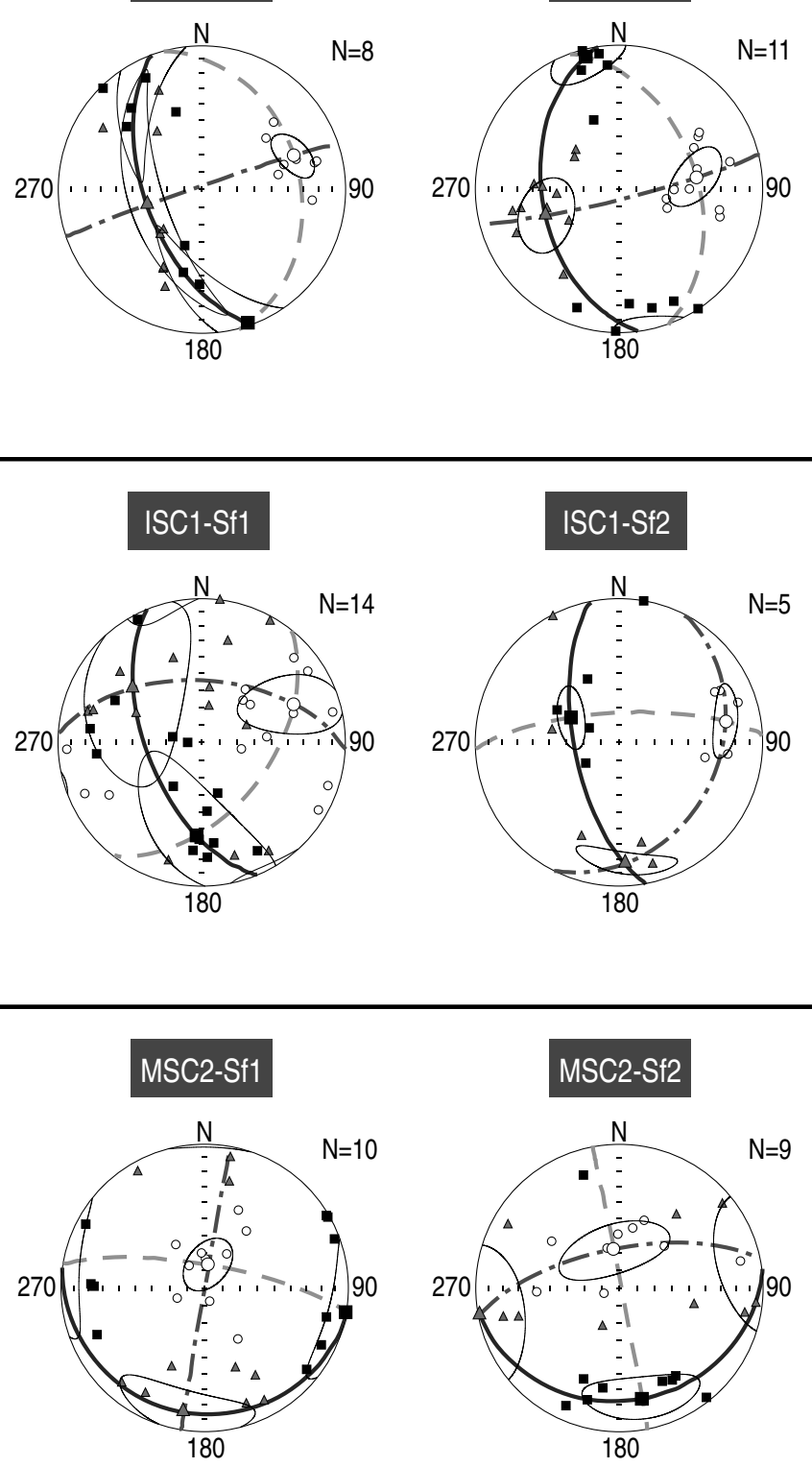

$N=11$

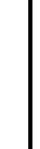

10

\begin{tabular}{|llll|}
\hline $\begin{array}{l}\text { Mean susceptibility } \\
\text { tensors and relative }\end{array}$ & $\square$ & $\mathrm{k}_{1}$ - magnetic lineation & - Magnetic foliation $\left(\mathrm{k}_{1}-\mathrm{k}_{2}\right.$ plane $)$ \\
confidence ellipse: & $\bigcirc$ & $\mathrm{k}_{2}$ - intermediate axis & $---\mathrm{k}_{2}-\mathrm{k}_{3}$ plane \\
& & $\mathrm{k}_{3}$ - magnetic foliation pole & $--\mathrm{k}_{1}-\mathrm{k}_{3}$ plane \\
\hline
\end{tabular}

Figure 5: Magnetic fabric from the frontal thrust ramp at Sassotetto, Monastero (sites MSC1 and MSC2) and Infernaccio. Equal area projections in geographic coordinates of the principal magnetic susceptibility axes at site level (left) and relative subfabrics (middle and right). 


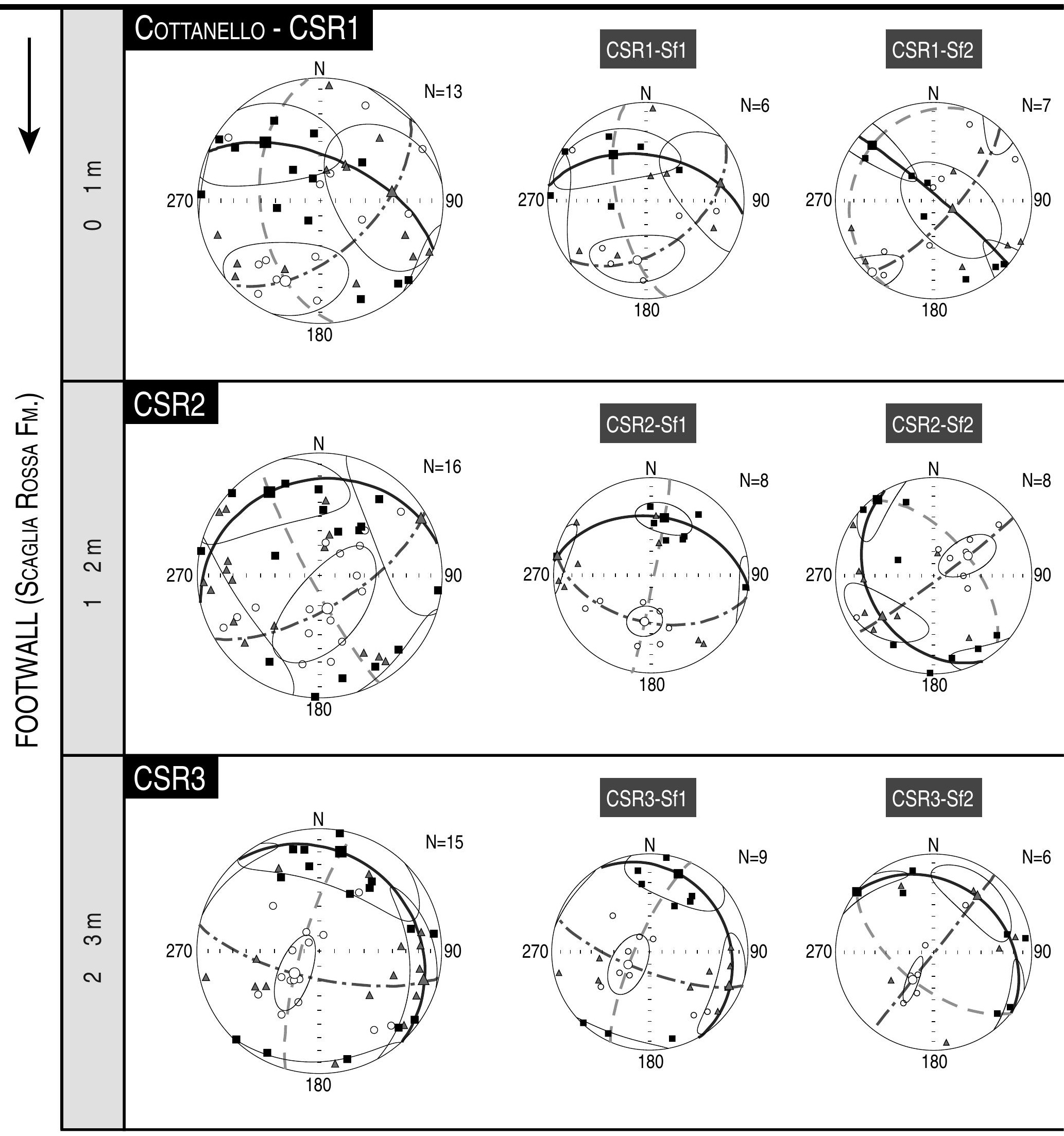

Figure 8: Magnetic fabric from the back-thrust at Cottanello. Equal area proje tions in geographic coordinates of the principal magnetic susceptibility axes at si level (left) and relative subfabrics (middle and right). Legend as in Figure 5. 
Figure $9 \longdiv { S } / C$ fabric evolution Frontal thrust ramp

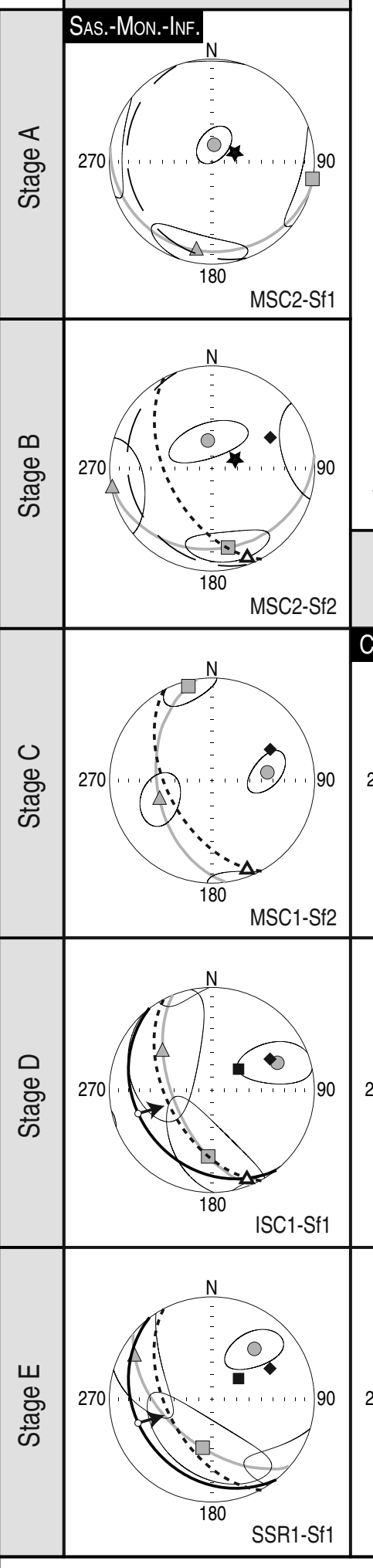

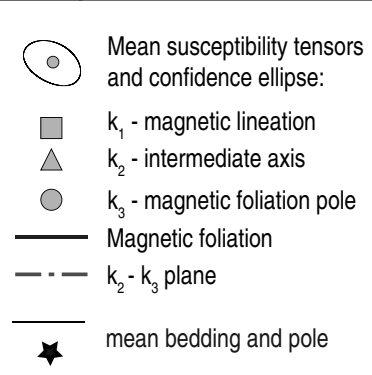

武

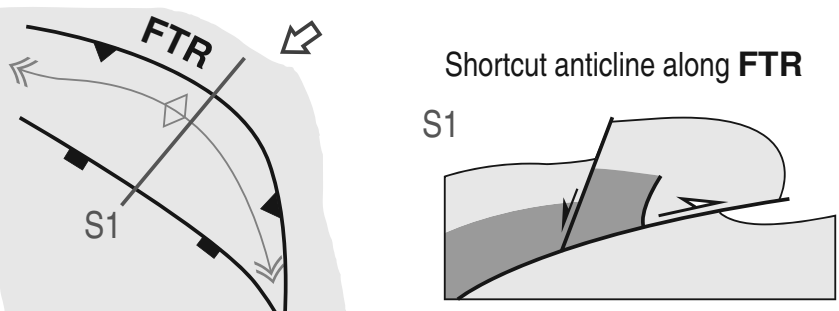

च

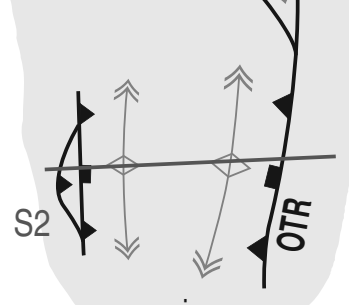

map view
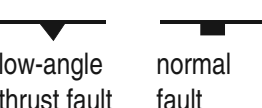

fault

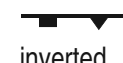

inverted normal fault

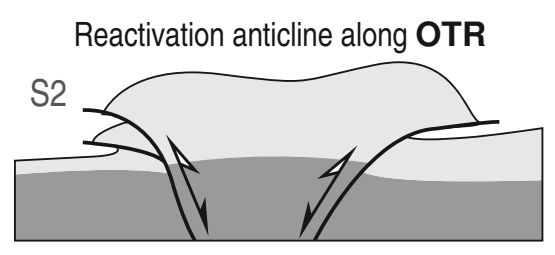

$S / C$ fabric - frontal thrust ramp dominant simple shear

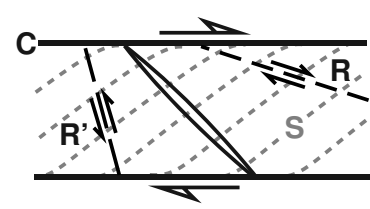

low-angle extensional shear bands

S/C fabric - back thrust dominant simple shear

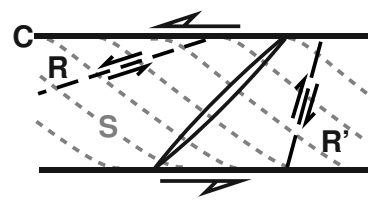

low-angle extensional shear bands

$S$ fabric - oblique thrust ramp dominant pure shear Back thrust

\section{Cottanello}
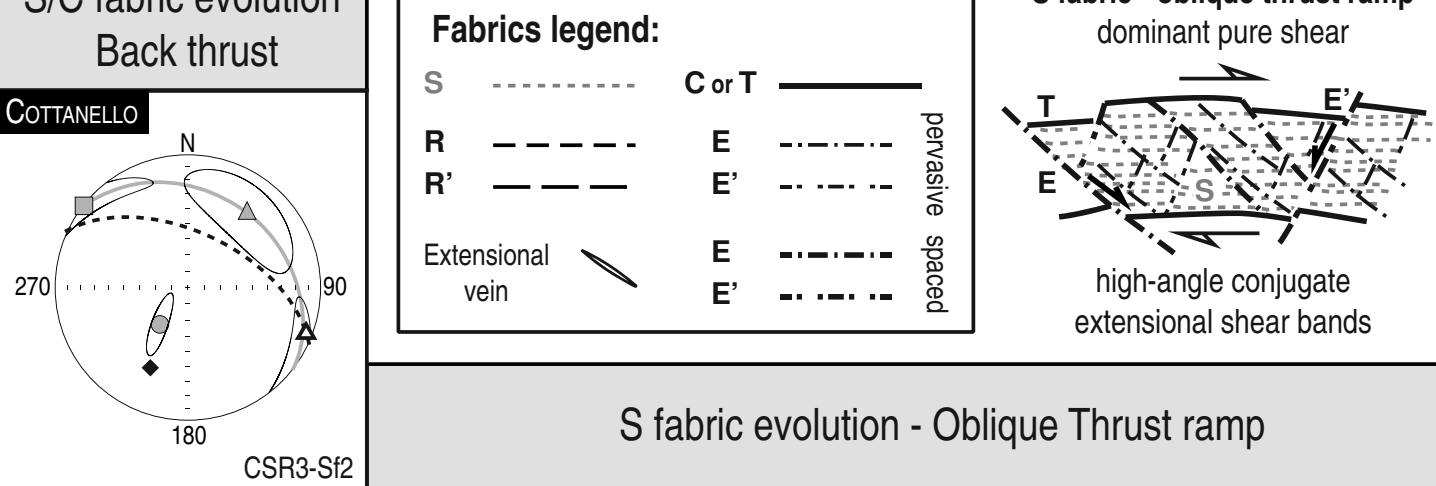

high-angle conjugate extensional shear bands

S fabric evolution - Oblique Thrust ramp

\section{Boragine VAlLESCURA}
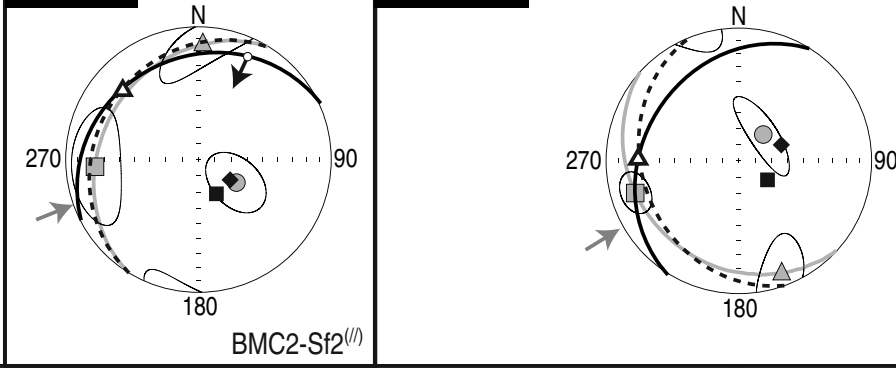

VMC2-Sf1 ${ }^{(/)}$
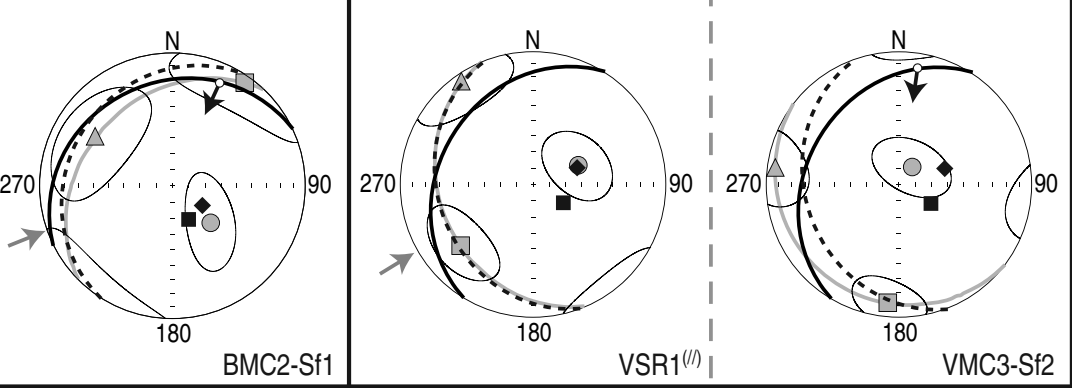

$\Delta \quad \mathrm{S} / \mathrm{C}$ or $\mathrm{S} / \mathrm{T}$ intersection

$\Delta \quad E / E$ ' intersection

c) computed slip vector

Transport direction

- mean shear (C) or thrus

(T) planes and poles

..... mean pressure solution

cleavage (S) and pole

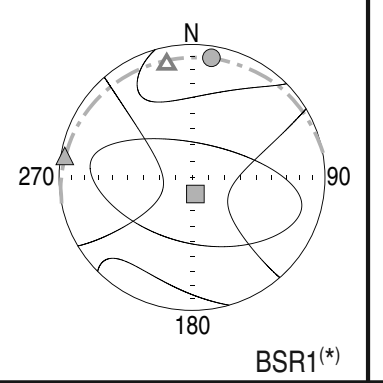

VSR2-Sf2

Figure 9: Summary of magnetic fabric stages and comparison with structural data. Representative examples from the different deformation regimes are reported. Conceptual diagram of the different types of shear deformation fabric (ZX section of strain ellipses) related to frontal (FTR) and oblique (OTR) thrust ramps (modified from Calamita et al., 2012; Pace et al., 2015). 
Supplementary material - Table 2
Click here to download Supplementary material for online publication only: SupTable2_.xlsx

Supplementary material - Table 2
Click here to download Supplementary material for online publication only: SupTable2_.xIsx .

che

(1)
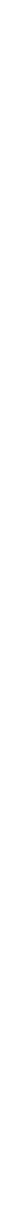


\section{Declaration of interests}

$\bigotimes$ The authors declare that they have no known competing financial interests or personal relationships that could have appeared to influence the work reported in this paper.

$\square$ The authors declare the following financial interests/personal relationships which may be considered as potential competing interests: 


\section{Author contributions}

SS: Project administration, funding acquisition, conceptualization, field work, methodology, laboratory analysis, structural analysis, writing - original draft.

CRT: field work, laboratory analysis, data curation, structural analysis, methodology, formal analysis, writing - original draft, data visualization

DS: field work, laboratory analysis, writing - review and editing

EZ: supervision, funding acquisition, field work, writing - original draft, data visualization

FC: field work, structural analysis, writing - review and editing

ET: field work, laboratory analysis, writing - review and editing 